Impacts of climate change on geographical distributions of invasive ascidians

$4 \quad$ Running title

5 Climate change impacts ascidian distributions

\title{
Authors
}

Zhixin Zhang ${ }^{1}$, César Capinha², Dirk N. Karger ${ }^{3}$, Xavier Turon ${ }^{4}$, Hugh J. MacIsaac ${ }^{5,6}$, Aibin Zhan ${ }^{7,8}$

\section{Affiliation and address}

${ }^{1}$ Graduate School of Marine Science and Technology, Tokyo University of Marine Science and 


\section{Abstract}

Ocean warming derived from global climate change renders marine ecosystems susceptible to biological invasions. Here, we projected habitat suitability of eight highly invasive ascidians under present-day and future climate scenarios. The mean sea surface temperature was predicted as the most important environmental factor affecting distributions. SDM projection results indicated that the tested ascidians might respond differently to future climate change. Alarmingly, the currently colonized areas are much smaller than predicted. So far, a lower number of invasive ascidians have been detected in some areas such as South American coasts. Such findings suggest that these aforementioned areas have a high risk of new invasions. In contrast, African coasts, excluding the Mediterranean side, are not prone to new invasions. Our results highlight the importance of impacts of climate change on future invasions and the need for accurate modelling of invasion risks, which can be used as a guide to develop management strategies.

\section{Keywords}

benthos; biological invasion; climate change; habitat; management strategy; species distribution model. 


\section{INTRODUCTION}

Biological invasions have been recognized as one of the most serious threats to global biodiversity and have resulted in substantial ecological changes, health effects, and economic impacts (Pimentel et al., 2005; Ehrenfeld, 2010; Simberloff et al., 2013; Scheele et al., 2019). Invasive species can negatively impact native communities through competition and predation (Ehrenfeld, 2010; Simberloff et al., 2013; Zhan et al., 2015). In addition, they are capable of transmitting parasites and pathogens that cause fatal diseases and declines of native species (e.g., Kozubíková et al., 2009; Scheele et al., 2019). Marine ecosystems are extremely susceptible to biological invasions owing to several factors, notably intensive human activities such as global shipping and both direct and indirect effects of climate changes (Stachowicz et al., 2002; Molnar et al., 2008; Olenin et al., 2011). Approximately $90 \%$ of global trade relies on ships, transferring organisms via biofouling and ballast water among coastal waters (Molnar et al., 2008; Kaluza et al., 2010; Goldsmit et al., 2018).

Additionally, ocean warming has affected a number of large marine ecosystems worldwide (Lyman et al., 2010; Rhein et al., 2014). According to the IPCC Fifth Assessment Report, for example, the upper $75 \mathrm{~m}$ of the global ocean has warmed at a rate of about $0.11^{\circ} \mathrm{C}$ per decade from 1971 to 2010 (Rhein et al., 2014). Owing to a combination of species' range shifts derived from climate change and arrivals of new species, changes in marine communities are often detected in coastal regions (Stachowicz et al., 2002; Perry et al., 2005; Cheung et al., 2009; Raitsos et al., 2010; Sorte et al., 2010). Previous studies have confirmed that native and invasive species have different responses to environmental stressors; often, but not always, invasive species exhibit broader ecological tolerance, thus ocean warming can result in superior performance of the latter over the former (Stachowicz et al., 2002; Braby and Somero, 2006; Fields et al., 2006; Sorte et al., 2010; Anacleto et al., 2014). For instance, Stachowicz et al. (2002) demonstrated that, compared with native ascidians, ocean warming was expected to facilitate an earlier and more intense recruitment, as well as a higher growth rate, of 
introduced ascidians, which might lead to changes in benthic community structure. Sorte et al. (2010) also found that introduced species had higher thermal tolerance, survival, and growth than natives in a marine fouling community, and accordingly they suggested that introduced species were likely to dominate the fouling community with ocean warming. Considering the great susceptibility of marine habitats to biological invasions jointly caused by high propagule pressure (i.e., introduction effort) as a result of shipping activities and warming as a result of climate change, it is important to identify potential distributions of marine invaders under present and future climate conditions for implementation of management strategies at early invasion stages.

A large number (> 80 species globally) of ascidians (Chordata, Tunicata) are notorious invasive species, affecting marine ecosystem functioning, local biodiversity, and industries such as aquaculture and fisheries owing to their superior competitive ability, growth rate, and broad environmental tolerance (Blum et al., 2007; Lambert, 2007; Shenkar and Swalla, 2011; Aldred and Clare, 2014; Zhan et al., 2015). Ascidians generally have limited natural dispersal ability, with the recent large-scale spread primarily attributed to human-mediated activities such as shipping and mariculture (Lambert, 2001; Marins et al., 2010; Zhan et al., 2015). Thus far, few studies have been conducted to map areas susceptible to ascidian invasions (but see Herborg et al., 2009; Locke, 2009; Madariaga et al., 2014; Lins et al., 2018). Additionally, despite the recognition that climate change may favour invasions by ascidians (Stachowicz et al., 2002; Sorte et al., 2010; Rius et al., 2014), its effects on ascidian distributions have received relatively little attention (but see Goldsmit et al., 2018). The objective of the present study is to investigate the impacts of climate changes on habitat suitability of eight globally-distributed invasive ascidians: Botrylloides violaceus, Botryllus schlosseri, Ciona savignyi, Didemnum vexillum, Microcosmus squamiger, Molgula manhattensis, Styela clava, Styela plicata. We chose these invasive ascidians as they have wide ranges of distribution, high availability of occurrence data, and great impacts on recipient ecosystems (Zhan et 
al., 2015). To analyse the impact of climate changes on the potential distribution of these invaders, we used ensemble species distribution models (SDMs). SDMs are a powerful tool to estimate species habitat suitability by capturing the relationship between species distribution data and environmental predictor variables (Guisan and Thuiller, 2005; Guisan et al., 2017). Recently, SDMs have been increasingly used to examine climate change impacts on marine species, including invasive species (e.g., Assis et al., 2018a; Buonomo et al., 2018; Goldsmit et al., 2018; Moraitis et al., 2018; de la Hoz et al., 2019). For instance, Goldsmit et al. (2018) used SDMs to study impacts of climate changes on potential distributions of eight aquatic invasive species in the Canadian Arctic, and found that climate changes could result in poleward gains in habitat suitability.

Here, we aim to substantially expand current knowledge about the present-day and future global distributions of the aforementioned invasive ascidians. Specifically, we (1) constructed ensemble SDMs for each ascidian species by using species distribution data and marine predictor variables; (2) evaluated relative contribution of each predictor variable to ascidian distributions to identify critical variables regulating ascidian distributions; and (3) predicted habitat suitability for each ascidian species under present and projected future climatic scenarios. Results of our study have important implications for prioritizing resource allocation for the prevention and control of invasive ascidians under a changing climate.

\section{MATERIALS AND METHODS}

\subsection{Study area and species occurrence records}

Several previous studies have highlighted that the extent of study area can influence the outcome of SDMs (VanDerWal et al., 2009; Barve et al., 2011), thus it is a good practice to consider spatial extent of the study area (Lins et al., 2018). Ascidians are mainly distributed in near-shore waters, thus as in Lins et al. (2018), we considered only areas within the Exclusive Economic Zone (i.e., within 
$370 \mathrm{~km}$ of the coast).

Georeferenced occurrence records of each ascidian species were collected from the literature and multiple online databases, including the Global Biodiversity Information Facility (http://www.gbif.org) (GBIF.org, 2019), the Ocean Biogeographic Information System (http://iobis.org) (OBIS, 2019), the NBN Atlas (https://nbnatlas.org) (NBN Atlas, 2019), the USGS Biodiversity Information Serving Our Nation (https://bison.usgs.gov) (U.S. Geological Survey, 2019), the Atlas of Living Australia (http://www.ala.org.au) (Atlas of Living Australia, 2019), and the Archive for Marine Species and Habitats Data (www.dassh.ac.uk). All above online databases were accessed on November 20, 2019. Previous studies have identified the problem posed by sampling bias in species occurrence records and the need to reduce it (Syfert et al., 2013; Boria et al., 2014). In order to match with the spatial resolution of marine predictor variables (see section 2.2 for details), we randomly selected only one occurrence record per 5 arcminute grid cell. After this data cleaning procedure, a total of 3,189 occurrence records (ranging from 77 to 1,367 records per species; Supporting Information Fig. S1a-S8a) were retained for downstream analyses.

\subsection{Current and future marine predictor variables}

Habitat suitability of marine organisms can be accurately predicted by a few variables (Belanger et al., 2012; Bosch et al., 2018; Goldsmit et al., 2018). Given the information available under present and future scenarios, 20 predictor variables were considered: water depth, distance to the shore, and annual mean and range values (minimum values, maximum values, maximum values - minimum values, average of the minimum and maximum values per year) of sea surface temperature, salinity, and current velocity (see Assis et al., 2018b for details; Supporting Information Fig. S9). Water depth and distance to the shore were obtained from the Global Marine Environment Datasets (http://gmed.auckland.ac.nz) (Basher et al., 2014), while the other 18 environmental variables were 
downloaded from Bio-ORACLE v2.0 (http://www.bio-oracle.org) (Assis et al., 2018b). Present marine environmental predictors from Bio-ORACLE v2.0 represent average values for the period 2000 -2014 (Assis et al., 2018b). Collinearity of predictor variables can severely influence the parameter estimates in a regression framework (Dormann et al. 2013). We therefore estimated collinearity of the 20 predictor variables by calculating Pearson's correlation coefficients $(r)$ and selected only one among highly correlated variables (i.e., $|r|>0.7$, Dormann et al. 2013); consequently, nine predictor variables (i.e. water depth, distance to shore, annual mean temperature, range values of temperature, annual mean salinity, range values of salinity, annual mean current velocity, maximum values of current velocity, and minimum values of current velocity) were used to develop SDMs (Supporting Information Fig. S9). Water depth and distance to the shore were included in our analyses since SDMs without considering these two variables would fail to distinguish the known distribution patterns of ascidians (Supporting Information Fig. S1c-S8c).

Future projections of the seven environmental predictor variables retained for 2050s (2040-2050) and 2100s (2090-2100) under four greenhouse gas emission scenarios [i.e., representative concentration pathway (RCP), RCP26, RCP45, RCP60, and RCP85] were also obtained from BioORACLE v2.0 (Assis et al., 2018b). Thus far, there is no available dataset for future water depth and distance to the shore; therefore, in this study, we assume that the two geographical variables, water depth and distance to the shore, will remain constant under future conditions. Although we acknowledge that climate change is expect to result in sea-level rise and the two geographical variables will change accordingly in the future, our SDM projections can still provide useful information about ascidian invasion risks. For the purpose of reducing uncertainties, three atmosphere-ocean general circulation models (i.e., CCSM4, HadGEM2-ES, MIROC5) were considered and their average values were used to represent future climate conditions (Assis et al., 2018b). 


\subsection{Modelling procedures}

A variety of SDM algorithms have been developed so far, but inter-algorithmic variation is still the highest source of uncertainty in future projections of species ranges (Thuiller et al., 2019). Therefore, we used an ensemble modelling approach, which is acknowledged as preferable than the application of a single algorithm, owing to its ability to combine results of different models, to account for the prediction uncertainties (Araújo and New, 2007; Guisan et al., 2017). We considered ten modelling algorithms with their default settings in the "biomod2" R package: artificial neural network (ANN), classification tree analysis (CTA), flexible discriminant analysis (FDA), generalized additive model (GAM), generalized boosting model (GBM), generalized linear model (GLM), multiple adaptive regression splines (MARS), maximum entropy (Maxent), random forest (RF), and surface range envelop (SRE) (Thuiller et al., 2014; Guisan et al., 2017). Several of these algorithms utilize species presence-absence (1-0) data. True absence data is always difficult to acquire, thus we adopted 10,000 randomly generated pseudo-absence points within the study area as an alternative (Thuiller et al., 2014; Guisan et al., 2017). A five-fold cross-validation scheme was applied to estimate predictive performances of the ten SDM algorithms: each algorithm was trained using $80 \%$ of the data and tested using the remaining 20\% (Thuiller et al., 2014; Guisan et al., 2017). To account for slight differences in the predictions caused by stochasticity in some of the algorithms, this procedure was repeated ten times for each algorithm. Predictive abilities of different algorithms were evaluated by two criteria: true skill statistics (TSS) (Allouche et al., 2006) and area under the receiver operating characteristic curve (AUC) (Swets, 1988). The TSS values range from -1 to 1 , where a value $\leq 0$ indicates that the model gives a random prediction, and a value of 1 indicates a perfect model performance (Landis and Koch, 1977). The AUC scores range from 0 to 1 , with values $<0.5$ indicating performance worse than random, a value of 0.5 indicating predictions no better than 
random discrimination, and 1 representing perfect discrimination (Swets, 1988; Allouche et al., 2006). Algorithms with TSS $>0.75$ and AUC $>0.90$ were further considered in this study (Landis and Koch, 1977; Swets, 1988). The relative contribution of each predictor variable on ascidian distribution was assessed by a randomisation approach (Thuiller et al., 2014; Guisan et al., 2017). Committee averaging ensemble models were developed by using all data, which in turn were used to map the habitat suitability of ascidians under present and future climate scenarios. The committee averaging method represents the level of agreement among binary predictions of suitability from the different single algorithms (Thuiller et al., 2014; Guisan et al., 2017). In order to establish a threshold for declaring an area as suitable habitat, the continuous predictions of habitat suitability, which ranged from 0 to 1 , were converted into binary maps by selecting probability thresholds maximizing the TSS (Jiménez-Valverde and Lobo, 2007; Thuiller et al., 2014; Guisan et al., 2017). Thus, we did not adopt a fixed threshold value, but rather sought to find an optimal threshold for each species. The coefficient of variation across single SDM predictions was calculated to estimate uncertainty among model outputs (Thuiller et al., 2014; Guisan et al., 2017). Previous studies have demonstrated that species dispersal capability can influence SDM projections (Guisan et al., 2017). In this study, we estimated habitat suitability of ascidians assuming no dispersal limitations (also known as unlimited dispersal ability hypothesis) - a widely used hypothesis: species have unlimited dispersal ability thus can occur in climatic suitable areas. To estimate the range size of suitable habitats, projections in geographic coordinate system were transformed to the Lambert Cylindrical Equal Area projection with a grid cell resolution of $10 \mathrm{~km}$ x $10 \mathrm{~km}$. All analyses were carried out in R 3.4.3 (R Core Team, 2017).

\section{RESULTS}

\subsection{Predictive accuracy of SDMs and contribution of predictor variables}


AUC and TSS results demonstrated that predictive abilities of SDMs varied among different modelling algorithms and that all algorithms except GAM, Maxent and SRE had excellent predictive performance for all eight ascidian species (Supporting Information Table S1, S2). Therefore, the seven best-performing algorithms, including ANN, CTA, FDA, GBM, GLM, MARS, and RF, were selected to evaluate variable importance and to construct ensemble SDMs. The ensemble SDMs exhibited excellent predictive power for all eight ascidians as evidenced by the high AUC $(>0.99)$ and TSS ( $>0.94)$ values (Table 1). Results of relative contributions of the nine predictor variables to the potential distributions of ascidians suggest that despite the fact that the eight ascidian species have different environmental requirements, water depth, distance to the shore, and annual mean sea surface temperature were consistently identified as the three most important variables for all species tested (overall means of importance $=0.267,0.431$, and 0.443 , respectively), followed by range of annual mean surface temperature and mean salinity (mean importance across species: 0.093 and 0.078); whereas mean current velocity, minimum current velocity, maximum current velocity, and range of annual sea surface salinity consistently contributed least to the distributions (mean importance $=$ 0.008, 0.014, 0.015, and 0.028, respectively; Fig. 1).

Table 1 Predictive performance of ensemble species distribution models for eight ascidian species and suitable habitat ranges of each species under present-day climate. TSS: true skill statistics; AUC: area under the receiver operating characteristic curve. The predictive abilities are expressed as mean values \pm standard error. The range of suitable habitat is represented by the number of raster cells (i.e., $100 \mathrm{~km}^{2}$ ) predicted to be suitable for each species.

\begin{tabular}{cccc}
\hline Species & AUC & TSS & Number of raster cells \\
\hline Botrylloides violaceus & $0.992( \pm 0.001)$ & $0.959( \pm 0.005)$ & 22,644 \\
Botryllus schlosseri & $0.992( \pm 0.001)$ & $0.948( \pm 0.001)$ & 28,624
\end{tabular}




$\begin{array}{cccc}\text { Ciona savignyi } & 0.999( \pm 0.000) & 0.993( \pm 0.004) & 4,048 \\ \text { Didemnum vexillum } & 0.996( \pm 0.001) & 0.972( \pm 0.004) & 14,747 \\ \text { Microcosmus squamiger } & 0.996( \pm 0.002) & 0.965( \pm 0.014) & 5,904 \\ \text { Molgula manhattensis } & 0.994( \pm 0.001) & 0.956( \pm 0.003) & 37,744 \\ \text { Styela clava } & 0.995( \pm 0.001) & 0.966( \pm 0.001) & 15,915 \\ \text { Styela plicata } & 0.993( \pm 0.001) & 0.960( \pm 0.004) & 28,100\end{array}$
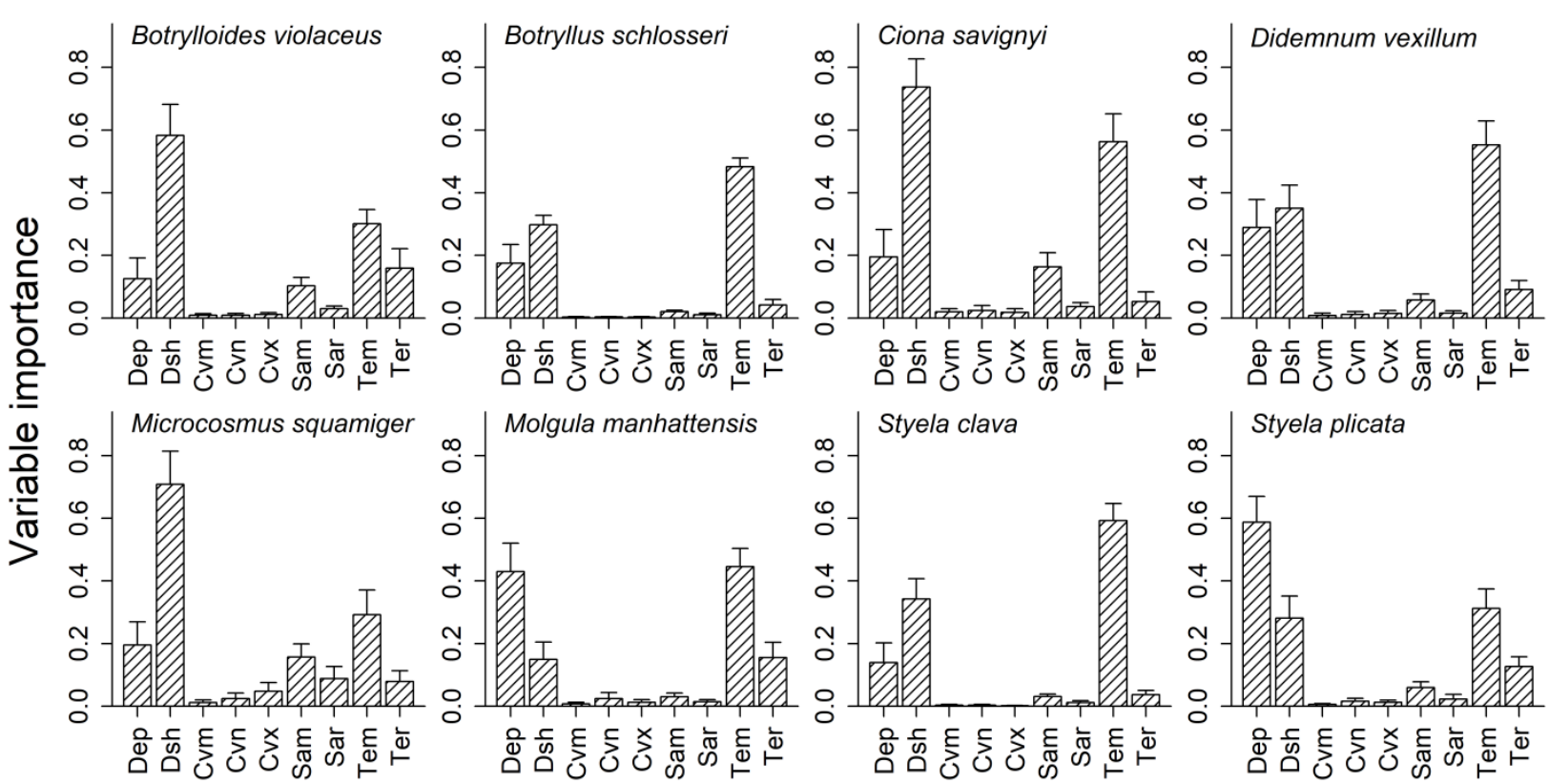

Fig. 1 Relative contributions of the nine predictor variables to distributions of eight ascidians. Dep: water depth, Dsh: distance to the shore, Cvm: mean current velocity, Cvn: minimum current velocity,

Cvx: maximum current velocity, Sam: annual mean salinity, Sar: range of annual mean salinity, Tem: annual mean sea surface temperature, Ter: range of annual mean sea surface temperature. Data is expressed as mean values \pm standard error.

\subsection{Habitat suitability under present-day climates}

The coefficient of variation of species habitat suitability predicted by single SDMs showed that 
variability in species occurrence probability within suitable ranges was relatively small and significantly lower than that within unsuitable ranges (Supporting Information Fig. S1b-S8b). The eight ascidians were predicted to have different ranges of suitable habitat under present-day climates: M. manhattensis has the largest suitable habitat followed by B. schlosseri, S. plicata, and B. violaceus, while suitable ranges of $C$. savignyi and M. squamiger were predicted to be the smallest (Table 1). Interestingly, the eight ascidians showed important differences in the distribution of suitable areas. For example, in Europe, the suitable habitats of $B$. violaceus and $D$. vexillum were predicted to occur mainly along coastal areas of Atlantic side of the north Iberian Peninsula, Atlantic coast of France, the United Kingdom, Ireland, Belgium, Netherlands Denmark, and Norway, whereas coastal areas of the Mediterranean Sea were most suitable for M. squamiger (Supporting Information Fig. S1a-S8a). Despite the different geographical ranges of climatically suitable habitats, the eight ascidians all preferred shallow, nearshore waters. It is important to note that under present-day conditions, these species have not yet fully occupied their predicted suitable habitats (Supporting Information Fig. S1aS8a). For instance, B. violaceus, $D$. vexillum, and $S$. clava have not been reported in the South America, though southern coastal Argentina and Chile present suitable habitats for these species (Supporting Information Fig. S1a, S4a, S7a). According to our predictions, a number of coastal regions have high susceptibility to invasions by the studied ascidians, including the coastal areas of China, Japan, Australia, New Zealand, North America, southern South America, the Mediterranean Sea, and the Atlantic coast of Europe. In contrast, invasion risk of ascidians in Africa was much lower than that in the regions mentioned above (Supporting Information Fig. S1a-S8a, S10).

\subsection{Impacts of climate changes on ascidian distributions}

The eight ascidians responded differently to future climate changes (Fig. 2). The range size of $D$. vexillum was predicted to contract in 2050s but expand in 2100s under the four RCP scenarios; the 
range sizes were expected to decrease for B. schlosseri, M. squamiger, and S. plicata, but expand for the other four species under future climate conditions (Fig. 2). Regardless of the time periods and RCP scenarios selected, $C$. savignyi was predicted to experience the highest habitat expansion, from
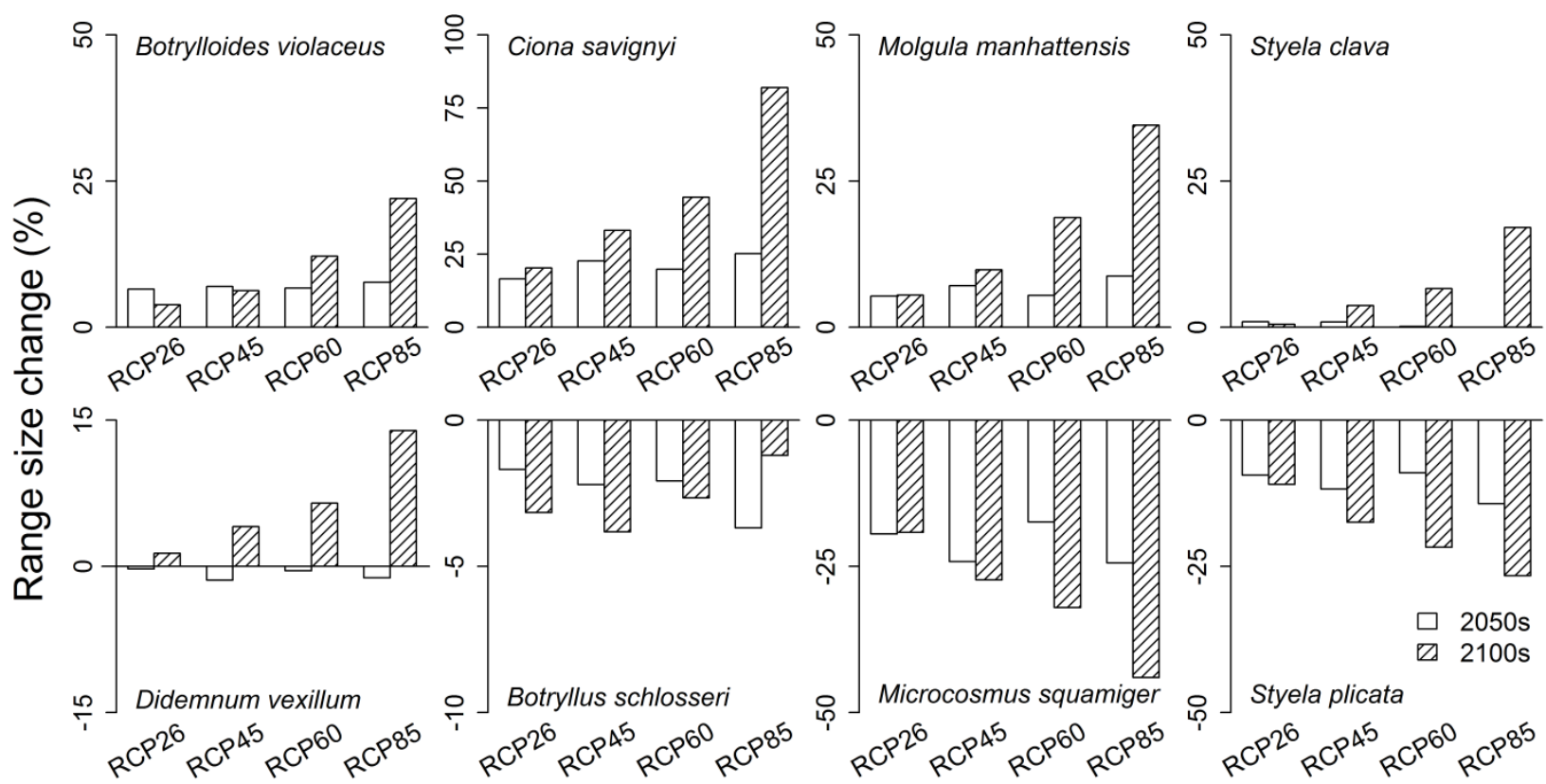

Fig. 2 Range size changes of the eight ascidians under future climates. RCP: representative concentration pathway. 2050s: 2040-2050, 2100s: 2090-2100.

Here we used the results for the 2050s under an intermediate greenhouse gas emission scenario (i.e., RCP45) as an example to illustrate potential climate change impacts on ascidian distributions. Under these plausible conditions, an extensive part of European coasts was predicted to be suitable for the eight ascidian species (Fig. 3, Table 2). These models highlighted that the northern Atlantic coast was more susceptible to invasions, especially by $B$. violaceus, $B$. schlosseri, $D$. vexillum, $M$. 


\begin{tabular}{ccccc}
\hline \multirow{2}{*}{ Species } & \multicolumn{4}{c}{ Present-day suitable range and range change under RCP45 in 2050s } \\
\cline { 2 - 5 } & Americas & Europe & Western Pacific & Africa \\
\hline B. violaceus & $8,966(9.6 \%)$ & $5,441(7.2 \%)$ & $7,349(5.6 \%)$ & $694(-12.2 \%)$ \\
B. schlosseri & $8,591(12.3 \%)$ & $11,767(-9.5 \%)$ & $7,170(-6.0 \%)$ & $774(-12.5 \%)$ \\
C. savignyi & $1,725(45.4 \%)$ & $825(55.3 \%)$ & $1,504(-16.6 \%)$ & $24(-33.3 \%)$ \\
D. vexillum & $5,327(18.1 \%)$ & $5,484(-6.6 \%)$ & $3,471(-22.4 \%)$ & $372(-22.8 \%)$ \\
M. squamiger & $1,333(-20.4 \%)$ & $1,780(-49.7 \%)$ & $1,806(-1.9 \%)$ & $769(-27.4 \%)$ \\
M. manhattensis & $14,378(12.3 \%)$ & $12,237(6.0 \%)$ & $10,402(1.6 \%)$ & $630(-20.5 \%)$ \\
S. clava & $5,111(26.9 \%)$ & $5,774(-3.6 \%)$ & $4,543(-20.1 \%)$ & $355(-26.5 \%)$ \\
S. plicata & $9,135(-17.3 \%)$ & $5,557(9.8 \%)$ & $9,679(-9.2 \%)$ & $2,961(-32.3 \%)$
\end{tabular}

manhattensis, and S. clava (Fig. 3, Table 2). Additional spread of S. plicata was forecasted to be limited to the United Kingdom, Ireland and the Netherlands. However, species range increases in Northern Europe may be offset by losses in the southern part of the continent owing to reduced suitability (Table 2). For example, suitable habitat along the Mediterranean Sea was likely to decrease under RCP45 in 2050s for all ascidians except C. savignyi and S. plicata, whose habitats were expected to remain nearly unchanged (Fig. 3).

Table 2 Suitable habitat ranges of each species under present-day climate and range size change (percentage values in parentheses) under RCP45 in 2050s. Four regions (i.e. Americas, Europe, Western Pacific, and Africa) were divided as shown in Figure 3, 4, 5, and S10. Range size change was calculated as: (suitable range under RCP45 in 2050s - present-day suitable range)/present-day suitable range. Suitable habitat range is represented by the number of raster cells (i.e., $100 \mathrm{~km}^{2}$ ) predicted to be suitable for each species.

Present-day suitable range and range change under RCP45 in 2050s 

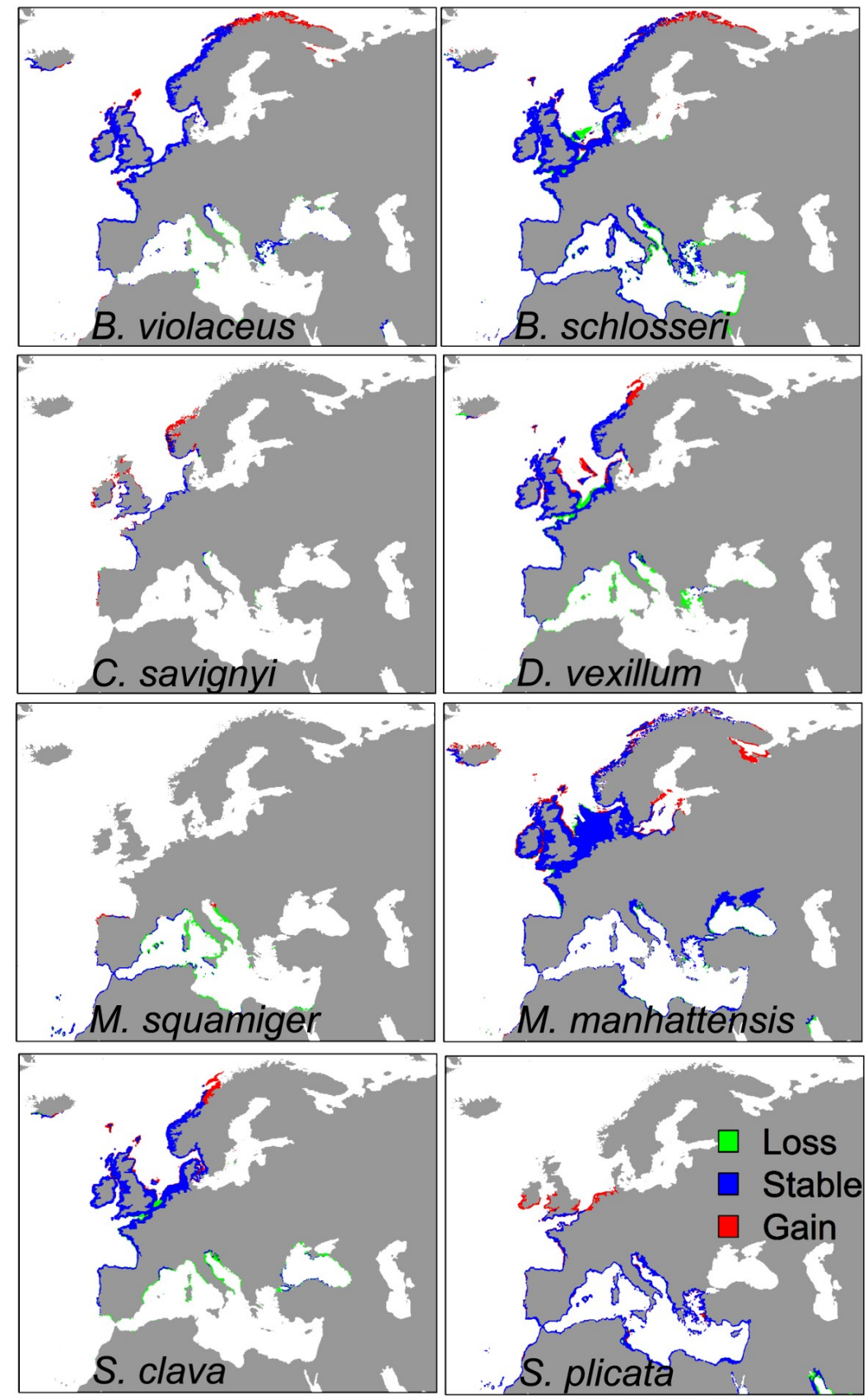

Fig. 3 Predicted range shifts of the eight ascidians in Europe in 2050s under RCP45 scenario. RCP: representative concentration pathway. 2050s: 2040-2050. Stable areas (in blue) indicate habitats that are predicted to be suitable under both present-day and future climates; loss areas (in green) show areas which are predicted to be no longer suitable in the future; gain areas (in red) represent habitats that are predicted to become suitable in the future. 
Concerning the coasts of North and South America, model predictions highlighted that large 303 coastal regions - except for the tropics - would be suitable for all ascidians (Fig. 4, Table 2). Suitable 304 habitats of M. squamiger and S. plicata were predicted to contract under future climates (Table 2). encounter suitable habitat only north of the Tropic of Cancer in the northern hemisphere and south of the Tropic of Capricorn in the southern hemisphere; north of the Tropic of Capricorn, all species Habitats of six species, including B. violaceus, B. schlosseri, C. savignyi, D. vexillum, $M$. manhattensis, and S. clava, were expected to exhibit a poleward expansion, especially along the Gulf of Alaska, Gulf of Saint Lawrence, and Patagonia (Fig. 4). Most ascidians were projected to except S. plicata were expected to experience suitable habitats only on the west coast, if at all (Fig. 4). 


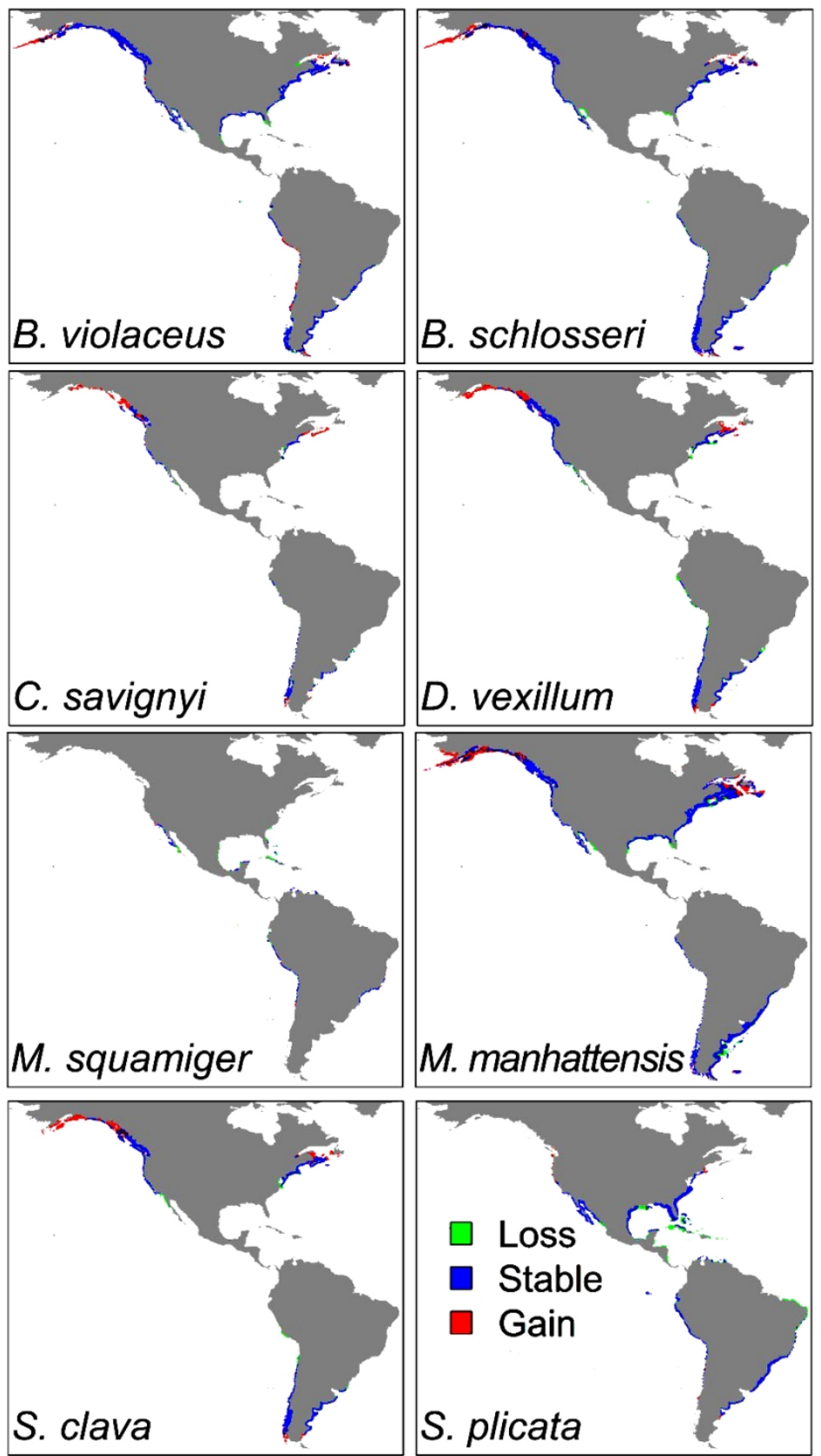

312 Fig. 4 Predicted range shifts of the eight ascidians in the Americas in 2050s under RCP45 scenario.

313 RCP: representative concentration pathway. 2050s: 2040-2050. Stable areas (in blue) indicate

314 habitats that are predicted to be suitable under both present-day and future climates; loss areas (in

315 green) show areas which are predicted to be no longer suitable in the future; gain areas (in red)

316 represent habitats that are predicted to be suitable in the future. 
The coasts of China, Korea, and Japan were predicted under future climate change scenarios to

319 be suitable habitats for all eight ascidians. Seven species, including B. violaceus, B. schlosseri, C.

320 savignyi, D. vexillum, M. manhattensis, S. clava, and S. plicata, will generally lose habitat suitability

321 in East Asia and, owing to climate changes, all these species except S. plicata would extend their

322 habitats further north in Hokkaido in Northern Japan (Fig. 5). The coasts of Australia and New

323 Zealand were expected to remain susceptible to invasions by all ascidians in 2050 s, with little

324 expected changes in patterns (Fig. 5). M. squamiger and S. plicata habitat might expand to include

325 Tasmania and adjacent coastal mainland Australia, as well as the South Island of New Zealand. In

326 addition, S. plicata would experience loss of suitable habitats in some regions of Northern Australia. 

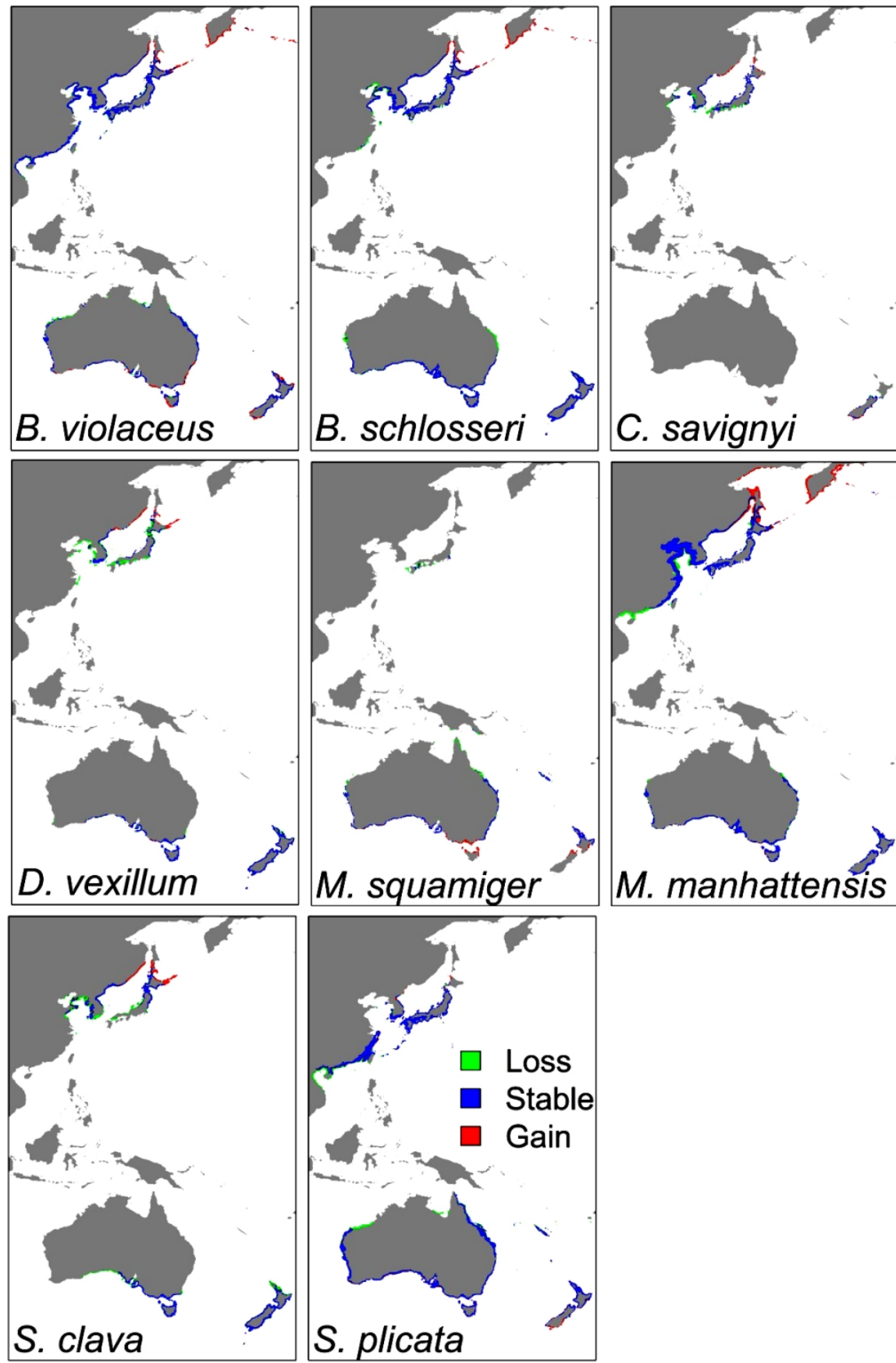

Fig. 5 Predicted range shifts of the eight ascidians along coastal areas of the Western Pacific in 2050s under RCP45 scenario. RCP: representative concentration pathway. 2050s: 2040-2050. Stable areas (in blue) indicate habitats that are predicted to be suitable under both present-day and future climates; loss areas (in green) show areas which are predicted to be no longer suitable in the future; gain areas (in red) represent habitats that are predicted to be suitable in the future. 


\section{Discussion}

In this study, we developed ensemble SDMs for eight invasive ascidian species and investigated climate change impacts on their global potential distributions. Ensemble SDMs showed good predictive abilities and indicated that the eight ascidians have not yet colonized the full extent of their present-day suitable habitats worldwide. Our models also predicted that these species would behave differently under future climate scenarios. Our results hold important implications for developing management strategies for these highly invasive ascidians.

Among the nine predictor variables chosen to construct SDMs, distance to the shore, water depth, and annual mean sea surface temperature were the top three influential predictors of ascidian distributions. As these species are mainly restricted to shallow, nearshore habitats, it was not surprising that two geographical variables were predicted to play critical roles in regulating their distributions. Our finding regarding the importance of annual mean sea surface temperature is in agreement with previous studies (Belanger et al., 2012; Bosch et al., 2018; Goldsmit et al., 2018). Furthermore, Belanger et al. (2012) demonstrated that mean annual temperature was the most important predictor variable regulating benthic marine biogeographic structure. Similarly, using SDMs, Bosch et al. (2018) provided convincing evidence that the mean sea surface temperature was the most relevant predictor of global distributions for 514 marine species.

Water salinity also strongly influences ascidian development and distributions (Thiyagarajan and Qian, 2003; Epelbaum et al., 2009; Locke and Carman, 2009; Nagar and Shenkar, 2016). In our study, ensemble SDMs highlighted that the effect of salinity was not nearly as strong as that of temperature in any of the eight ascidian species. Such difference was mainly due to the limited variation of salinity in our study areas. We focused only on coastal areas within the Exclusive Economic Zone. Within this area, mean sea surface temperature was evenly distributed and covered a wide range from -1.7 to $30.2{ }^{\circ} \mathrm{C}$, whereas mean sea surface salinity mainly varied only between 30 and $38 \%$ (Supporting 
Information Fig. S11). This relatively minor variation in mean sea surface salinity might partly account for our model's failure to highlight the importance of salinity in affecting ascidian distributions.

According to our SDM predictions, the eight ascidians displayed different distribution patterns under present-day climates (Supporting Information Fig. S1a-S8a) and were expected to respond differently to future climate changes (Fig. 3-5). Under present-day climates, predicted suitable habitats of the eight ascidians were often larger than their current known distribution ranges. This finding is consistent with several previous SDM studies on ascidians (Herborg et al., 2009; Goldsmit et al., 2018; Lins et al., 2018). Several possible factors including dispersal limitation and sampling bias have been proposed to explain this phenomenon (see Goldsmit et al. 2018). Owing to intensive human activities such as global shipping, invasion risks of M. manhattensis, B. schlosseri, B. violaceus, S. plicata, D. vexillum, and S. clava induced by such activities were expected to be high due to their large area of suitable habitats, while risks of M. squamiger and C. savignyi spread were relatively low (Fig. 3-5). These findings are troubling because several biological features of ascidians such as a relative short planktonic larval phase (usually minutes to several days) lead to a high level of dispersal limitation, particularly at regional and continental scales (Zhan et al., 2015). Thus, great care must be taken to ensure that intensive human activities such as shipping and aquaculture do not facilitate further spread of these invasive species to uncolonized areas.

Future climate changes are likely to result in changes in habitat suitability. Overall, we predicted a poleward expansion of these warm-temperate species, with loss of suitable habitats on the warmer trailing edges. This is a feature commonly predicted for marine organisms (Perry et al., 2005; Cheung et al., 2009) and for ascidians as well (Tracy et al., 2017). Our results support the findings by Goldsmit et al. (2018), who estimated climate change impacts on habitat suitability of eight invaders including B. violaceus in the Canadian Arctic. Their results predicted suitable habitat of B. violaceus 
to increase by $17.1 \%$ under RCP45 emission scenario by mid-century, with a poleward shift. Shifts in species ranges related to climate changes have been documented or projected for many marine species (Perry et al., 2005; Vermeijj and Roopnarine, 2008; Cheung et al., 2009; Assis et al., 2018a; Chan et al., 2019). Such distribution shifts can pose great threats to marine ecosystems by altering species interactions, and to humans dependent on living marine resources. For instance, a coastal fish species distributed along the west coast of southern Africa experienced a southward distributional shift during ocean warming, resulting in hybridization with its local congeners (Potts et al., 2014). Moreover, a ten-year study in eastern Australia demonstrated that ocean warming increased the proportion of herbivorous fishes in kelp forests, which in turn led to the loss of kelp (Vergés et al., 2016). Species loss as a result of direct and indirect effects of the new invaders, as well as hybridization with native species on the newly colonized areas, allow biological changes to persist even if the initiating driver (climate change) has waned. Further studies are required to investigate the impacts of distribution shifts of invasive ascidians on native ecosystems.

According to our SDM predictions under future climate scenarios, four ascidians were expected to expand their geographic ranges while geographical distributions of three species were likely to contract. These different responses to climate changes might reflect different environmental tolerance among these ascidians. It is noteworthy that the eight species investigated have a warm-temperate distribution range, yet diverse responses to climate change were predicted. This may indicate the high sensitivity of our modelling approach to nuances in tolerance limits of the species that can be detected only after careful analysis of their distribution patterns. Similar results were also detected in other aquatic organisms. For example, Van Zuiden et al. (2016) used SDMs to identify species-specific responses to climate change by fishes from three thermal guilds in Ontario, Canada. Species-specific environmental tolerance to temperature and salinity has been previously investigated in several ascidian species (see Pineda et al., 2012; Madariaga et al., 2014; Rius et al., 2014). Further studies are 
required to examine environmental preferences of ascidians and confirm whether these ascidians display different thresholds of environmental tolerance.

A crucial point in all modelling approaches is the correctness of taxonomic assignments. For broadly distributed taxa, there is always the possibility that unrecognized cryptic speciation can confound analyses, and this is particularly true for ascidians (e.g., Teske et al., 2011; Zhan et al., 2012; Pérez-Portela et al., 2013). In our target species, genetic evidence provided confidence that we dealt with single species entities in most cases (Botrylloides violaceus, Bock et al., 2011; Ciona savignyi, Griggio et al., 2014, Nydam and Harrison, 2007; Didemnum vexillum, Stefaniak et al., 2009; Microcosmus squamiger, Rius et al., 2012; Molgula manhattensis, Haydar et al., 2011; Styela clava, Goldstien et al., 2011; Styela plicata: Pineda et al., 2011). For Botryllus schlosseri, however, concern exists about its taxonomic status and the accuracy of existing reports, as the species has been shown to comprise several genetic clades (Bock et al., 2012; Nydam et al., 2017) and speciation processes may be ongoing in some clades (Griggio et al., 2014). Even though reference databases may confound different clades of this species complex, we are confident that most records correspond to the widespread and invasive clade (i.e., Clade A in Bock et al., 2012). Thus, our results should be still valid in this regard, though caution should be applied in this case. In addition, it is important to note that SDMs only capture correlations between species distribution data and environmental variables but do not account for different life-history characteristics (Guisan and Thuiller, 2005; Guisan et al., 2017; Briscoe et al., 2019). For instance, ascidians have diverse reproductive modes (from asexual to sexual reproduction) (Zhan et al., 2015) and SDMs cannot incorporate these differences. Processexplicit models may represent an alternative to overcome these barriers (Briscoe et al., 2019).

Another important conclusion of our analyses is the contrasting distribution forecasts for South America and Africa. The former presents a large fraction of already suitable habitats that have not been colonized by the species studied, and was forecasted to experience poleward gains of suitable 
habitats in the future, particularly in the Atlantic and Pacific coasts of the Patagonian region. This region emerges, therefore, as a high-risk area and one suitable for enhanced surveillance and pathway control. On the contrary, African coasts (excluding the Mediterranean side) have a low present-day risk of invasions by the studied species and the situation is unlikely to change appreciably in the future, so this continent is, for the time being, of least concern in this respect. However, important shipping ports, such as those in South Africa, can change this picture rapidly as warming increases (Rius et al., 2014). Consequently, those hot spots should be closely monitored.

Our results highlight the importance of climate change impacts on invasive ascidian distributions and can be used as a guide to develop management strategies given that these organisms are among the most troublesome invaders in the sea. SDM predictions indicated that invasion risks of the eight ascidians were mainly concentrated along coastal areas of the Americas, Europe, East Asia, and Australasia. In areas where ascidians have already become established, physical and chemical eradication methods are required to protect marine ecosystems (Zhan et al., 2015). In areas less likely to be suitable for ascidian colonization under future climates - such as coasts of the Mediterranean Sea for B. schlosseri and M. squamiger and East Asia for D. vexillum and M. manhattensis prevention measures may be most effective. Eradication of established invasive species is very difficult and always requires long-term economic and social supports, and this is also the case for ascidians (e.g., Forrest and Hopkins, 2013; Sambrook et al., 2014). Therefore, effective prevention approaches should focus on curtailing initial spread to uncolonized regions (Olenin et al., 2011; Zhan et al., 2015). It should be noted that invasive ascidians tend to colonize artificial habitats; however, we could not incorporate artificial habitats into SDMs owing to the lack of data availability. Urbanized coasts may have higher risks to receive invasions in predicted suitable habitats by SDMs (Airoldi et al., 2015). Consequently coasts in urbanized areas should be prioritized to conduct surveillance and implement prevention programs. Environmental DNA (eDNA) has proven useful 
for early detection of invasive species (Dejean et al., 2012; Larson et al., 2017), and Zhan et al. (2015) proposed the method be used for invasive ascidians. However, additional work is required to develop highly sensitive, species-specific eDNA markers for the suite of ascidians now spreading globally (Simpson et al., 2017). Further global progress on limiting dispersal opportunities by ballast water and hull fouling is needed to curtail spread of ascidian species.

\section{Conclusions}

Modelling approaches hold a great potential to optimize prevention and management decisions. In this study, we found that the scope for expansion of invasive ascidian species was different and could be assessed by using the ensemble SDM approach. Our study predicted where ascidian species would and would not survive if introduced, and also identified high risk areas where monitoring and control efforts should be concentrated. We encourage the application of modelling procedures to forecast marine invasion dynamics and accordingly to develop management strategies such as early detection in high risk areas.

\section{Acknowledgements}

We would like to thank all members in Zhan Laboratory for their assistance in literature review for data collection. This work was supported by the National Natural Science Foundation of China (Nos. 31622011, 31772449) to AZ, the project CTM2017-88080 (MCIU/AEI/FEDER/UE) of the Spanish Government to XT, an NSERC Discovery grant and Canada Research Chair in Aquatic Invasive Species to HJM. CC was funded by National Funds through FCT, I.P., under the programme of 'Stimulus of Scientific Employment - Individual Support' within the contract

'CEECIND/02037/2017'. DNK received funding from the ERA-Net BiodivERsA - Belmont Forum, with the national funder Swiss National Foundation (20BD21_184131), part of the 2018 Joint call 
BiodivERsA-Belmont Forum call (project 'FutureWeb').

Conflict of Interest: The authors declare that they have no conflict of interest.

\section{References}

Airoldi, L., Turon, X., Perkol-Finkel, S., \& Rius, M. (2015). Corridors for aliens but not for natives: effects of marine urban sprawl at a regional scale. Diversity and Distributions, 21, 755-768. https://doi.org/10.1111/ddi.12301

Aldred, N., \& Clare, A. S. (2014). Impact and dynamics of surface fouling by solitary and compound ascidians. Biofouling, 30:259-270. https://doi.org/10.1080/08927014.2013.866653

Allouche, O., Tsoar, A., \& Kadmon, R. (2006). Assessing the accuracy of species distribution models: prevalence, kappa and the true skill statistic (TSS). Journal of Applied Ecology, 43, 1223-1232. https://doi.org/10.1111/j.1365-2664.2006.01214.X

Anacleto, P., Maulvault, A. L., Lopes, V. M., Repolho, T., Diniz, M., Nunes, M. L., Marques, A., \& Rosa, R. (2014). Ecophysiology of native and alien-invasive clams in an ocean warming context. Comparative Biochemistry and Physiology Part A: Molecular \& Integrative Physiology, 175, 28-37. https://doi.org/10.1016/j.cbpa.2014.05.003

Araújo, M. B., \& New, M. (2007). Ensemble forecasting of species distributions. Trends in Ecology and Evolution, 22, 42-47. https://doi.org/10.1016/j.tree.2006.09.010

Assis, J., Araújo, M. B., \& Serrão, E. A. (2018a). Projected climate changes threaten ancient refugia of kelp forests in the North Atlantic. Global Change Biology, 24, e55-e66. https://doi.org/10.1111/gcb.13818

Assis, J., Tyberghein, L., Bosch, S., Verbruggen, H., Serrão, E. A., \& De Clerck, O. (2018b). BioORACLE v2.0: Extending marine data layers for bioclimatic modelling. Global Ecology and Biogeography, 27, 277-284. https://doi.org/10.1111/geb.12693 
Atlas of Living Australia. (2019). Atlas of Living Australia website at http://www.ala.org.au. Accessed 20 November 2019

Barve, N., Barve, V., Jiménez-Valverde, A., Lira-Noriega, A., Maher, S. P., Peterson, A. T., Soberóna, J., \& Villalobos, F. (2011). The crucial role of the accessible area in ecological niche modeling and species distribution modeling. Ecological Modelling, 222, 1810-1819. https://doi.org/10.1016/j.ecolmodel.2011.02.011

Basher, Z., Bowden, D. A., \& Costello, M. J. (2014). Global marine environment dataset (GMED). Version 1.0 (Rev.01.2014). Available from http://gmed.auckland.ac.nz.

Belanger, C. L., Jablonski, D., Roy, K., Berke, S. K., Krug, A. Z., Valentine, J. W. 2012. Global environmental predictors of benthic marine biogeographic structure. Proceedings of the National Academy of Sciences, 109, 14046-14051. https://doi.org/10.1073/pnas.1212381109

Blum, J. C., Chang, A. L., Liljesthröm, M., Schenk, M. E., Steinberg, M. K., \& Ruiz, G. M. (2007). The non-native solitary ascidian Ciona intestinalis (L.) depresses species richness. Journal of Experimental Marine Biology and Ecology, 342, 5-14. https://doi.org/10.1016/j.jembe.2006.10.010

Bock, D. G., MacIsaac, H. J., \& Cristescu, M. E. (2012). Multilocus genetic analyses differentiate between widespread and spatially restricted cryptic species in a model ascidian. Proceedings of the Royal Society B: Biological Sciences, 279, 2377-2385. https://doi.org/10.1098/rspb.2011.2610

Bock, D. G., Zhan, A., Lejeusne, C., MacIsaac, H. J., \& Cristescu, M. E. (2011). Looking at both sides of the invasion: patterns of colonization in the violet tunicate Botrylloides violaceus. Molecular Ecology, 20, 503-516. https://doi.org/10.1111/j.1365-294X.2010.04971.x

Boria, R. A., Olson, L. E., Goodman, S. M., \& Anderson, R. P. (2014). Spatial filtering to reduce sampling bias can improve the performance of ecological niche models. Ecological Modelling, 
Bosch, S., Tyberghein, L., Deneudt, K., Hernandez, F., \& De Clerck, O. 2018. In search of relevant predictors for marine species distribution modelling using the MarineSPEED benchmark dataset. Diversity and Distributions, 24, 144-157. https://doi.org/10.1111/ddi.12668

Braby, C. E., \& Somero, G. N. (2006). Following the heart: temperature and salinity effects on heart rate in native and invasive species of blue mussels (genus Mytilus). Journal of Experimental Biology, 209, 2554-2566. https://doi.org/10.1242/jeb.02259

Briscoe, N. J., Elith, J., Salguero-Gomez, R., Lahoz-Monfort, J. J., Camac, J. S., Giljohann, K. M., Holden, M. H., Hradsky, B. A., Kearney, M. R., McMahon, S. M., Phillips, B. L., Regan, T. J., Rhodes, J. R., Vesk, P. A., Wintle, B. A., Yen, J. D. L., Guillera-Arroita, G. (2019). Forecasting species range dynamics with process-explicit models: matching methods to applications. Ecology Letters, 22, 1940-1956. https://doi.org/10.1111/ele.13348

Buonomo, R., Chefaoui, R. M., Lacida, R. B., Engelen, A. H., Serrão, E. A., \& Airoldi, L. (2018). Predicted extinction of unique genetic diversity in marine forests of Cystoseira spp. Marine Environmental Research, 138, 119-128. https://doi.org/10.1016/j.marenvres.2018.04.013 Chan, F.T., Stanislawczyk, K., Sneekes, A.C., Dvoretsky, A., Gollasch, S., Minchin, D., David, M., Jelmert, A., Albretsen, J. \& Bailey, S.A. (2019) Climate change opens new frontiers for marine species in the Arctic: Current trends and future invasion risks. Global Change Biology, 25, 2538. https://doi.org/10.1111/gcb.14469

Cheung, W. W., Lam, V. W., Sarmiento, J. L., Kearney, K., Watson, R., \& Pauly, D. (2009). Projecting global marine biodiversity impacts under climate change scenarios. Fish and Fisheries, 10, 235-251. https://doi.org/10.1111/j.1467-2979.2008.00315.x

de la Hoz, C. F., Ramos, E., Puente, A., \& Juanes, J. A. (2019). Climate change induced range shifts in seaweeds distributions in Europe. Marine Environmental Research. 148, 1-11. 
552

Dejean, T., Valentini, A., Miquel, C., Taberlet, P., Bellemain, E., \& Miaud, C. (2012). Improved detection of an alien invasive species through environmental DNA barcoding: the example of the American bullfrog Lithobates catesbeianus. Journal of Applied Ecology, 49, 953-959. https://doi.org/10.1111/j.1365-2664.2012.02171.x

Dormann, C. F., Elith, J., Bacher, S., Buchmann, C., Carl, G., Carré, G., Marquéz, J. R. G., Gruber, B., Lafourcade, B., Leitão, P. J., Münkemüller, T., McClean, C., Osborne, P. E., Reineking, B., Schröder, B., Skidmore, A. K., Zurell, D., \& Lautenbach, S. (2013). Collinearity: a review of methods to deal with it and a simulation study evaluating their performance. Ecography, 36, 2746. https://doi.org/10.1111/j.1600-0587.2012.07348.x

Ehrenfeld, J. G. (2010). Ecosystem consequences of biological invasions. Annual Review of Ecology, Evolution, and Systematics, 41, 59-80. https://doi.org/10.1146/annurev-ecolsys-102209-144650

Epelbaum, A., Herborg, L. M., Therriault, T. W., \& Pearce, C. M. (2009). Temperature and salinity effects on growth, survival, reproduction, and potential distribution of two non-indigenous botryllid ascidians in British Columbia. Journal of Experimental Marine Biology and Ecology, 369, 43-52. https://doi.org/10.1016/j.jembe.2008.10.028

Fields, P. A., Rudomin, E. L., \& Somero, G. N. (2006). Temperature sensitivities of cytosolic malate dehydrogenases from native and invasive species of marine mussels (genus Mytilus): sequencefunction linkages and correlations with biogeographic distribution. Journal of Experimental Biology, 209, 656-667. https://doi.org/10.1242/jeb.02036

Forrest, B. M., \& Hopkins, G. A. (2013). Population control to mitigate the spread of marine pests: insights from management of the Asian kelp Undaria pinnatifida and colonial ascidian Didemnum vexillum. Management of Biological Invasions, 4, 317-326.

https://doi.org/10.3391/mbi.2013.4.4.06 
GBIF.org. (2019). GBIF occurrence download www.gbif.org. Accessed from R via dismo (https://CRAN.R-project.org/package=dismo) on 2019-11-20

Goldsmit, J., Archambault, P., Chust, G., Villarino, E., Liu, G., Lukovich, J. V., Barber, D. G., \& Howland, K. L. (2018). Projecting present and future habitat suitability of ship-mediated aquatic invasive species in the Canadian Arctic. Biological Invasions, 20, 501-517. https://doi.org/10.1007/s10530-017-1553-7

Goldstien, S. J., Dupont, L., Viard, F., Hallas, P. J., Nishikawa, T., Schiel, D. R., ... \& Bishop, J. D. (2011). Global phylogeography of the widely introduced North West Pacific ascidian Styela clava. PLoS ONE, 6, e16755. https://doi.org/10.1371/journal.pone.0016755

Griggio, F., Voskoboynik, A., Iannelli, F., Justy, F., Tilak, M. K., Xavier, T., ... \& Gissi, C. (2014). Ascidian mitogenomics: comparison of evolutionary rates in closely related taxa provides evidence of ongoing speciation events. Genome Biology and Evolution, 6, 591-605. https://doi.org/10.1093/gbe/evu041

Guisan, A., \& Thuiller, W. (2005). Predicting species distribution: offering more than simple habitat models. Ecology Letters, 8, 993-1009. https://doi.org/10.1111/j.1461-0248.2005.00792.x

Guisan, A., Thuiller, W., \& Zimmermann, N. E. (2017). Habitat Suitability and Distribution Models: With Applications in R. Cambridge University Press, Cambridge.

Haydar, D., Hoarau, G., Olsen, J. L., Stam, W. T., \& Wolff, W. J. (2011). Introduced or glacial relict? Phylogeography of the cryptogenic tunicate Molgula manhattensis (Ascidiacea, Pleurogona). Diversity and Distributions, 17, 68-80. https://doi.org/10.1111/j.1472-4642.2010.00718.x

Herborg, L. M., O’Hara, P., \& Therriault, T. W. (2009). Forecasting the potential distribution of the invasive tunicate Didemnum vexillum. Journal of Applied Ecology, 46, 64-72. https://doi.org/10.1111/j.1365-2664.2008.01568.x

Jiménez-Valverde, A., \& Lobo, J. M. (2007). Threshold criteria for conversion of probability of 
species presence to either-or presence-absence. Acta Oecologica, 31(3), 361-369. https://doi.org/10.1016/j.actao.2007.02.001

Kaluza, P., Kölzsch, A., Gastner, M. T., \& Blasius, B. (2010). The complex network of global cargo ship movements. Journal of the Royal Society Interface, 7, 1093-1103. https://doi.org/10.1098/rsif.2009.0495

Kozubíková, E., Filipová, L., Kozák, P., Ďuriš, Z., Martín, M. P., Diéguez-Uribeondo, J., Oidtmann, B., \& Petrusek, A. (2009). Prevalence of the crayfish plague pathogen Aphanomyces astaci in invasive American crayfishes in the Czech Republic. Conservation Biology, 23, 1204-1213. https://doi.org/10.1111/j.1523-1739.2009.01240.x

Lambert, G. (2001). A global overview of ascidian introductions and their possible impact on the endemic fauna. In: Sawada, H., Yokosawa, H., \& Lambert, C. C. (eds), The Biology of Ascidians. Tokyo, Springer-Verlag, 249-257.

Lambert, G. (2007). Invasive sea squirts: a growing global problem. Journal of Experimental Marine Biology and Ecology, 342, 3-4. https://doi.org/10.1016/j.jembe.2006.10.009

Landis, J. R., \& Koch, G. G. (1977). The measurement of observer agreement for categorical data. Biometrics, 33, 159-174. https://doi.org/10.2307/2529310

Larson, E. R., Renshaw, M. A., Gantz, C. A., Umek, J., Chandra, S., Lodge, D. M., \& Egan, S. P. (2017). Environmental DNA (eDNA) detects the invasive crayfishes Orconectes rusticus and Pacifastacus leniusculus in large lakes of North America. Hydrobiologia, 800, 173-185. https://doi.org/10.1007/s10750-017-3210-7

Lins, D. M., de Marco Jr, P., Andrade, A. F., \& Rocha, R. M. (2018). Predicting global ascidian invasions. Diversity and Distributions, 24, 692-704. https://doi.org/10.1111/ddi.12711

Locke, A. (2009). A screening procedure for potential tunicate invaders of Atlantic Canada. Aquatic Invasions, 4, 71-79. https://doi.org/10.3391/ai.2009.4.1.7 
Locke, A., \& Carman, M. (2009). In situ growth of the colonial ascidian Didemnum vexillum under different environmental conditions. Aquatic Invasions, 4, 275-278. https://doi.org/10.3391/ai.2009.4.1.27

Lyman, J. M., Good, S. A., Gouretski, V. V., Ishii, M., Johnson, G. C., Palmer, M. D., Smith, D. M., \& Willis, J. K. (2010). Robust warming of the global upper ocean. Nature, 465, 334-337. https://doi.org/10.1038/nature09043

Madariaga, D. J., Rivadeneira, M. M., Tala, F., \& Thiel, M. (2014). Environmental tolerance of the two invasive species Ciona intestinalis and Codium fragile: their invasion potential along a temperate coast. Biological Invasions, 16, 2507-2527. https://doi.org/10.1007/s10530-0140680-7

Marins, F. O., Novaes, R. L., Rocha, R. M., \& Junqueira, A. O. (2010). Non indigenous ascidians in port and natural environments in a tropical Brazilian bay. Zoologia, 27, 213-221. http://dx.doi.org/10.1590/S1984-46702010000200009

Molnar, J. L., Gamboa, R. L., Revenga, C., \& Spalding, M. D. (2008). Assessing the global threat of invasive species to marine biodiversity. Frontiers in Ecology and the Environment, 6, 485-492. https://doi.org/10.1890/070064

Moraitis, M. L., Tsikopoulou, I., Geropoulos, A., Dimitriou, P. D., Papageorgiou, N., Giannoulaki, M., Valavanis, V. D., Karakassis, I. (2018). Molluscan indicator species and their potential use in ecological status assessment using species distribution modeling. Marine Environmental Research, 140, 10-17. https://doi.org/10.1016/j.marenvres.2018.05.020

Nagar, L. R., \& Shenkar, N. (2016). Temperature and salinity sensitivity of the invasive ascidian Microcosmus exasperatus Heller, 1878. Aquatic Invasions, 11, 33-43. http://dx.doi.org/10.3391/ai.2016.11.1.04

NBN Atlas. (2019). NBN Atlas website at http://www.nbnatlas.org. Accessed 20 November 2019 
Nydam, M. L., Giesbrecht, K. B., \& Stephenson, E. E. (2017). Origin and dispersal history of two colonial ascidian clades in the Botryllus schlosseri species complex. PloS ONE, 12, e0169944. https://doi.org/10.1371/journal.pone.0169944

Nydam, M. L., \& Harrison, R. G. (2007). Genealogical relationships within and among shallowwater Ciona species (Ascidiacea). Marine Biology, 151, 1839-1847. https://doi.org/10.1007/s00227-007-0617-0

OBIS. (2019). Ocean Biogeographic Information System. Intergovernmental Oceanographic Commission of UNESCO. www.iobis.org. Accessed from R via robis (https://CRAN.Rproject.org/package=robis) on 2019-11-20

Olenin, S., Elliott, M., Bysveen, I., Culverhouse, P. F., Daunys, D., Dubelaar, G. B. J., Gollasch, S., Goulletquer, P., Jelmert, A., Kantor, Y., Mézeth, K. B., Minchin, D., Occhipint-Ambrogi, A., Olenina, I., Vandekerkhove, J. (2011). Recommendations on methods for the detection and control of biological pollution in marine coastal waters. Marine Pollution Bulletin, 62, 25982604. https://doi.org/10.1016/j.marpolbul.2011.08.011

Pérez-Portela, R., Arranz, V., Rius, M., \& Turon, X. (2013). Cryptic speciation or global spread? The case of a cosmopolitan marine invertebrate with limited dispersal capabilities. Scientific Reports, 3, 3197. https://doi.org/10.1038/srep03197

Perry, A. L., Low, P. J., Ellis, J. R., \& Reynolds, J. D. (2005). Climate change and distribution shifts in marine fishes. Science, 308, 1912-1915. https://doi.org/10.1126/science.1111322

Pineda, M. C., López-Legentil, S., \& Turon, X. (2011). The whereabouts of an ancient wanderer: global phylogeography of the solitary ascidian Styela plicata. PLoS ONE, 6, e25495. https://doi.org/10.1371/journal.pone.0025495

Pineda, M. C., McQuaid, C. D., Turon, X., López-Legentil, S., Ordóñez, V., \& Rius, M. (2012). Tough adults, frail babies: an analysis of stress sensitivity across early life-history stages of 
widely introduced marine invertebrates. PLOS ONE, 7, e46672.

https://doi.org/10.1371/journal.pone.0046672

Pimentel, D., Zuniga, R., \& Morrison, D. (2005). Update on the environmental and economic costs associated with alien-invasive species in the United States. Ecological Economics, 52, 273-288. https://doi.org/10.1016/j.ecolecon.2004.10.002

Potts, W. M., Henriques, R., Santos, C. V., Munnik, K., Ansorge, I., Dufois, F., Booth, A. J., Kirchner, C., Sauer, W. H., \& Shaw, P. W. (2014). Ocean warming, a rapid distributional shift, and the hybridization of a coastal fish species. Global Change Biology, 20, 2765-2777. https://doi.org/10.1111/gcb.12612

R Core Team. (2017). R: A language and environment for statistical computing. R Foundation for Statistical Computing, Vienna, Austria.

Raitsos, D. E., Beaugrand, G., Georgopoulos, D., Zenetos, A., Pancucci-Papadopoulou, A. M., Theocharis, A., \& Papathanassiou, E. (2010). Global climate change amplifies the entry of tropical species into the Eastern Mediterranean Sea. Limnology and Oceanography, 55, 14781484. https://doi.org/10.4319/1o.2010.55.4.1478

Rhein, M., Rintoul, S. R., Aoki, S., Campos, E., Chambers, D., Feely, R. A., Gulev, S., Johnson, G. C., Josey, S.A., Kostianoy, A., Mauritzen, C., Roemmich, D., Talley, L.D., \& Wang, F. (2014). Observations: Ocean. In: Climate Change 2013: The Physical Science Basis. Contribution of Working Group I to the Fifth Assessment Report of the Intergovernmental Panel on Climate Change [Stocker, T.F., Qin, D., Plattner, G. K., Tignor, M., Allen, S. K., Boschung, J., Nauels, A., Xia, Y., Bex, V., \& Midgley, P. M. (eds.)]. Cambridge University Press, Cambridge, United Kingdom and New York, NY, USA.

Rius, M., Clusella-Trullas, S., McQuaid, C. D., Navarro, R. A., Griffiths, C. L., Matthee, C. A., Heyden, S., \& Turon, X. (2014). Range expansions across ecoregions: interactions of climate 
change, physiology and genetic diversity. Global Ecology and Biogeography, 23, 76-88. https://doi.org/10.1111/geb.12105

Rius, M., Turon, X., Ordóñez, V., \& Pascual, M. (2012). Tracking invasion histories in the sea: facing complex scenarios using multilocus data. PLoS ONE, 7, e35815. https://doi.org/10.1371/journal.pone.0035815

Sambrook, K., Holt, R. H., Sharp, R., Griffith, K., Roche, R. C., Newstead, R. G., ... \& Jenkins, S. R. (2014). Capacity, capability and cross-border challenges associated with marine eradication programmes in Europe: The attempted eradication of an invasive non-native ascidian, Didemnum vexillum in Wales, United Kingdom. Marine Policy, 48, 51-58. https://doi.org/10.1016/j.marpol.2014.03.018

Scheele, B. C., Pasmans, F., Skerratt, L. F., Berger, L., Martel, A., Beukema, W., ... \& Canessa, S. (2019). Amphibian fungal panzootic causes catastrophic and ongoing loss of biodiversity. Science, 363, 1459-1463. https://doi.org/10.1126/science.aav0379

Shenkar, N., \& Swalla, B. J. (2011). Global diversity of Ascidiacea. PLoS ONE, 6, e20657. https://doi.org/10.1371/journal.pone.0020657

Simberloff, D., Martin, J. L., Genovesi, P., Maris, V., Wardle, D. A., Aronson, J., Courchamp, F., Galil, B., Garcia-Berthou, E., Pascal, M., Pyšek, P., Sousa, R., Tabacchi, E., Vilà, M. (2013). Impacts of biological invasions: what's what and the way forward. Trends in Ecology and Evolution, 28, 58-66. https://doi.org/10.1016/j.tree.2012.07.013

Simpson, T. J., Dias, P. J., Snow, M., Muñoz, J., \& Berry, T. (2017). Real-time PCR detection of Didemnum perlucidum (Monniot, 1983) and Didemnum vexillum (Kott, 2002) in an applied routine marine biosecurity context. Molecular Ecology Resources, 17, 443-453. https://doi.org/10.1111/1755-0998.12581

Sorte, C. J., Williams, S. L., \& Zerebecki, R. A. (2010). Ocean warming increases threat of invasive 
species in a marine fouling community. Ecology, 91, 2198-2204. https://doi.org/10.1890/100238.1

Stachowicz, J. J., Terwin, J. R., Whitlatch, R. B., \& Osman, R. W. (2002). Linking climate change and biological invasions: ocean warming facilitates nonindigenous species invasions. Proceedings of the National Academy of Sciences, 99, 15497-15500. https://doi.org/10.1073/pnas.242437499

Stefaniak, L., Lambert, G., Gittenberger, A., Zhang, H., Lin, S., \& Whitlatch, R. B. (2009). Genetic conspecificity of the worldwide populations of Didemnum vexillum Kott, 2002. Aquatic Invasions, 4, 29-44. https://doi.org/10.3391/ai.2009.4.1.3

Swets, J. A. (1988). Measuring the accuracy of diagnostic systems. Science, 240, 1285-1293. https://doi.org/10.1126/science.3287615

Syfert, M. M., Smith, M. J., \& Coomes, D. A. (2013). The effects of sampling bias and model complexity on the predictive performance of MaxEnt species distribution models. PloS ONE, 8 , e55158. https://doi.org/10.1371/journal.pone.0055158

Teske, P. R., Rius, M., McQuaid, C. D., Styan, C. A., Piggott, M. P., Benhissoune, S., ... \& Cooke, G. M. (2011). "Nested" cryptic diversity in a widespread marine ecosystem engineer: a challenge for detecting biological invasions. BMC Evolutionary Biology, 11, 176. https://doi.org/10.1186/1471-2148-11-176

Thiyagarajan, V., \& Qian, P. Y. (2003). Effect of temperature, salinity and delayed attachment on development of the solitary ascidian Styela plicata (Lesueur). Journal of Experimental Marine Biology and Ecology, 290, 133-146. https://doi.org/10.1016/S0022-0981(03)00071-6

Thuiller, W., Georges, D., \& Engler, R. (2014). biomod2: ensemble platform for species distribution modeling. $\mathrm{R}$ package version 3.3.7.

Thuiller, W., Guéguen, M., Renaud, J., Karger, D. N., \& Zimmermann, N. E. (2019). Uncertainty in 
ensembles of global biodiversity scenarios. Nature Communications, 10, 1446.

https://doi.org/10.1038/s41467-019-09519-w

Tracy, B. M., Larson, K. J., Ashton, G. V., Lambert, G., Chang, A. L., \& Ruiz, G. M. (2017).

Northward range expansion of three non-native ascidians on the west coast of North America. BioInvasions Record, 6, 203-209. https://doi.org/10.3391/bir.2017.6.3.04

U.S. Geological Survey. (2019). Biodiversity Information Serving Our Nation (BISON). Available at: https://bison.usgs.gov. Accessed 20 November 2019

VanDerWal, J., Shoo, L. P., Graham, C., \& Williams, S. E. (2009). Selecting pseudo-absence data for presence-only distribution modeling: how far should you stray from what you know? Ecological Modelling, 220, 589-594. https://doi.org/10.1016/j.ecolmodel.2008.11.010

Van Zuiden, T. M., Chen, M. M., Stefanoff, S., Lopez, L., \& Sharma, S. (2016). Projected impacts of climate change on three freshwater fishes and potential novel competitive interactions. Diversity and Distributions, 22, 603-614. https://doi.org/10.1111/ddi.12422

Vergés, A., Doropoulos, C., Malcolm, H. A., Skye, M., Garcia-Pizá, M., Marzinelli, E. M., Campbell, A. H., Ballesteros, E., Hoey, A. S., Vila-Concejo, A., Bozec, Y., \& Steinberg, P. D. (2016). Long-term empirical evidence of ocean warming leading to tropicalization of fish communities, increased herbivory, and loss of kelp. Proceedings of the National Academy of Sciences, 113, 13791-13796. https://doi.org/10.1073/pnas.1610725113

Vermeijj, G.J., \& and Roopnarine, P.D. (2008). The coming arctic invasion. Science, 321, 780-781. https://doi.org/10.1126/science.1160852

Zhan, A., Briski, E., Bock, D. G., Ghabooli, S., \& MacIsaac, H. J. (2015). Ascidians as models for studying invasion success. Marine Biology, 162, 2449-2470. https://doi.org/10.1007/s00227$015-2734-5$

Zhan, A., Darling, J. A., Bock, D. G., Lacoursiere-Roussel, A., MacIsaac, H. J., \& Cristescu, M. E. 

Evolution, 2, 1331-1346. https://doi.org/10.1002/ece3.258 


\section{Declaration of interests}

૫ The authors declare that they have no known competing financial interests or personal relationships that could have appeared to influence the work reported in this paper.

$\square$ The authors declare the following financial interests/personal relationships which may be considered as potential competing interests:

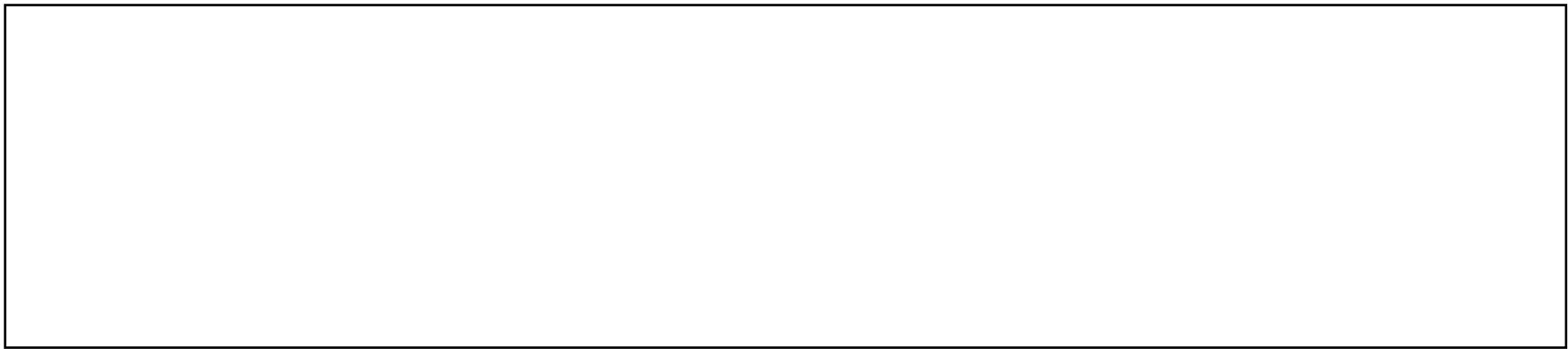




\section{Supporting Information}
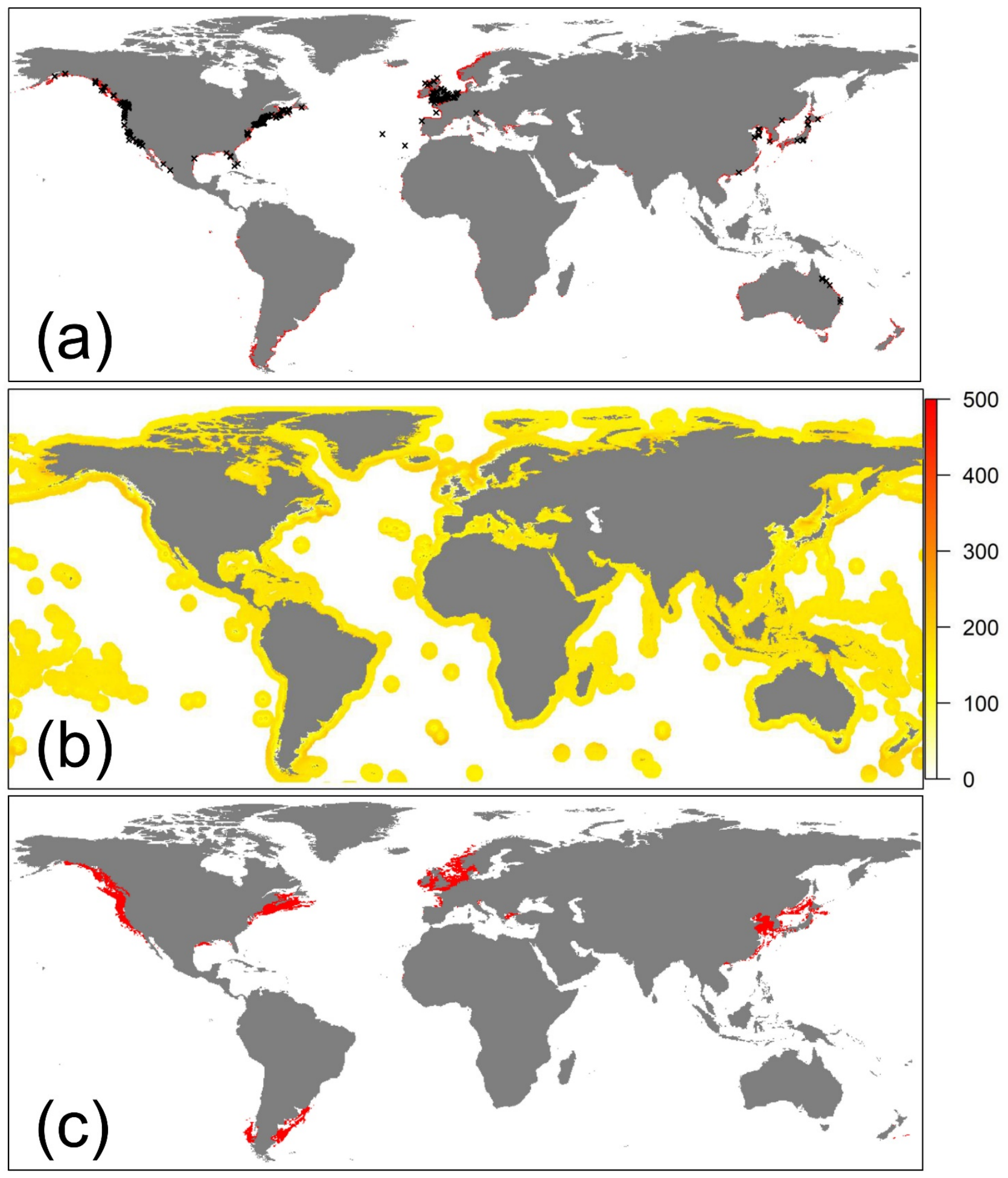
3 Figure S1. Habitat suitability of Botrylloides violaceus under present-day climate conditions.

4 Habitat suitability ranges from 0 to 1000 . Black crosses indicate occurrence records of $B$. violaceus

5 used to develop species distribution models. 341 occurrence records of $B$. violaceus were used.

$6 \quad$ Figure S1. (a) Suitable range of Botrylloides violaceus under present-day climate conditions

7 projected by ensemble SDM. Red area represents suitable range. Black crosses indicate occurrence

8 records of $B$. violaceus used to develop SDMs. 333 occurrence records of $B$. violaceus were used.

9 (b) Coefficient of variation of present-day species occurrence probability predicted by seven single

10 SDMs. Coefficient of variation in suitable range (i.e. red area in panel (a)) $(45.863 \pm 0.148)$ was

11 significantly lower than that in unsuitable range $(163.505 \pm 0.012)$ (Mann-Whitney $U$ Test; $p<$

$12 \underline{\left.2.2 \times 10^{-16}\right)}$. Results were expressed as mean \pm standard error. Coefficient of variation was calculated

13 as follows: coefficient of variation $=$ standard deviation $/$ mean*100\%. (c) Suitable range of $\underline{B}$.

14 violaceus under present-day climate conditions projected by ensemble SDM without considering 15 water depth and distance to shore. 

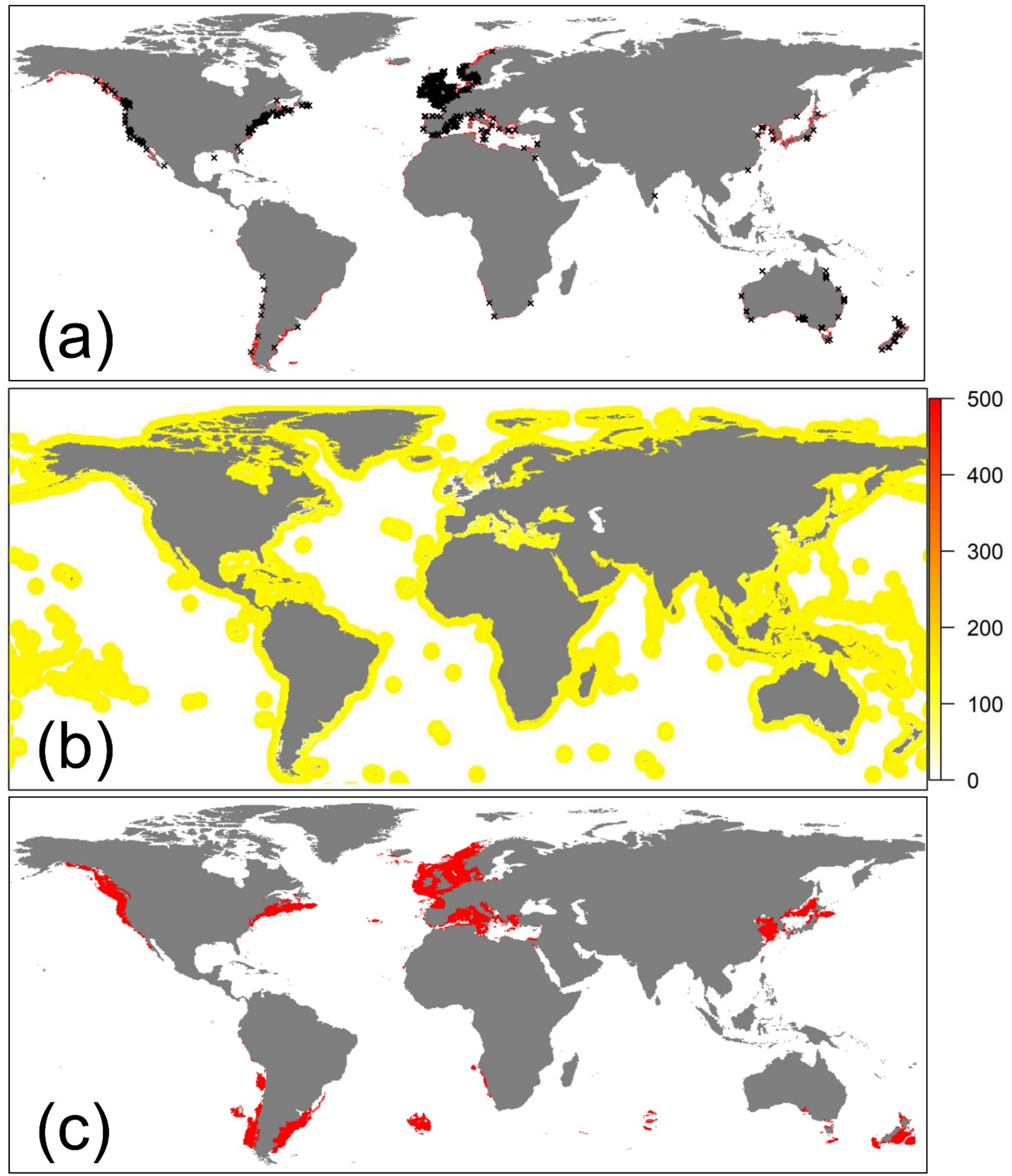

Figure S2. (a) Suitable range of Botryllus schlosseri under present-day climate conditions projected by ensemble SDM. Red area represents suitable range. Black crosses indicate occurrence records of B. schlosseri used to develop SDMs. 1367 occurrence records of B. schlosseri were used. (b) Coefficient of variation of present-day species occurrence probability predicted by seven single 
22 SDMs. Coefficient of variation in suitable range (i.e. red area in panel (a)) (35.885 \pm 0.113$)$ was 23 significantly lower than that in unsuitable range (136.869 \pm 0.010$)$ (Mann-Whitney $U$ Test; $p<$ $\left.2.2 \times 10^{-16}\right)$. Results were expressed as mean \pm standard error. Coefficient of variation was calculated as follows: coefficient of variation $=$ standard deviation $/$ mean* $100 \%$. (c) Suitable range of $B$. schlosseri under present-day climate conditions projected by ensemble SDM without considering water depth and distance to shore. 

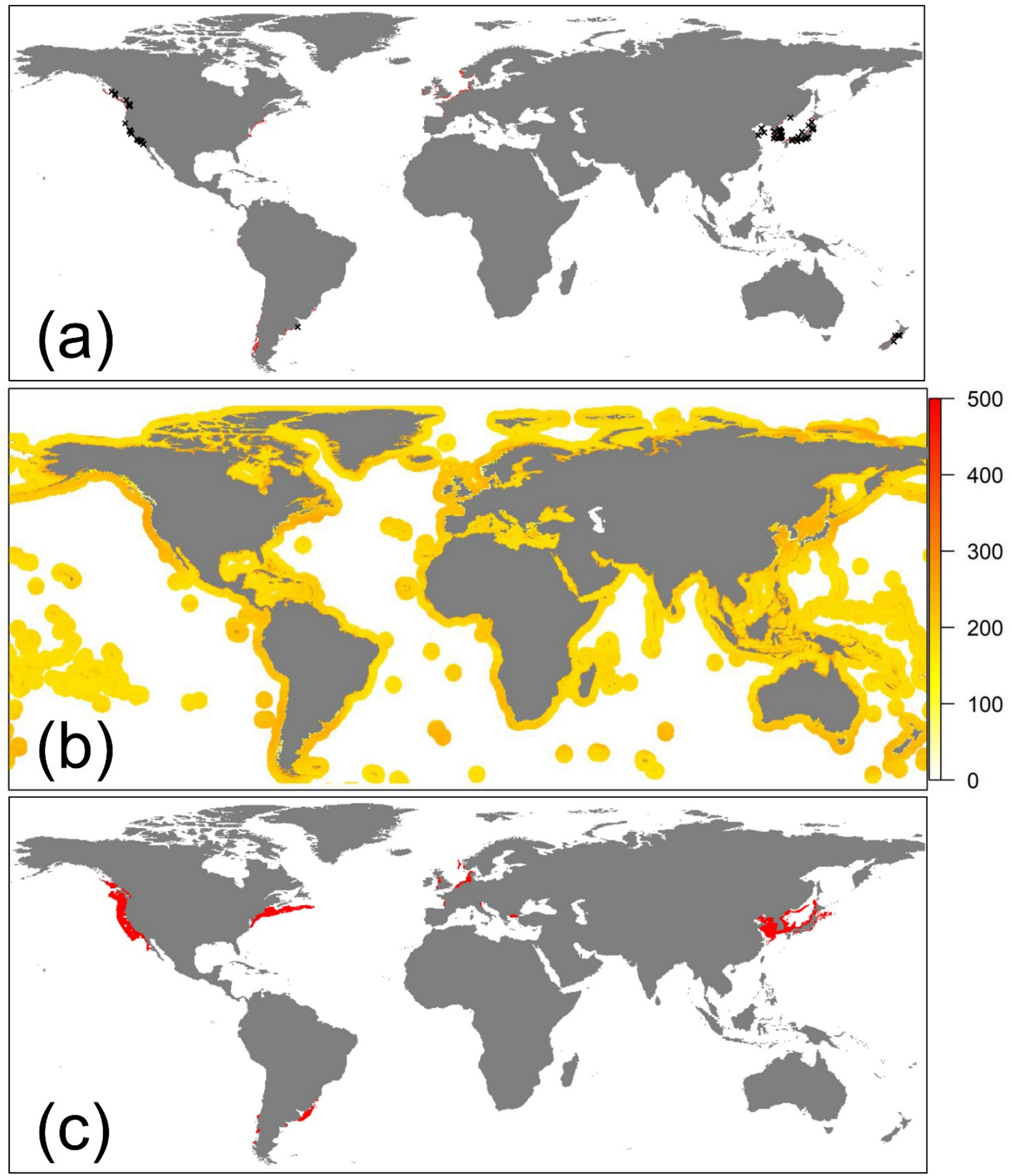

Figure S3. (a) Suitable range of Ciona savignyi under present-day climate conditions projected by ensemble SDM. Red area represents suitable range. Black crosses indicate occurrence records of $C$. savignyi used to develop SDMs. 93 occurrence records of $C$. savignyi were used. (b) Coefficient of variation of present-day species occurrence probability predicted by seven single SDMs. Coefficient 
34 of variation in suitable range (i.e. red area in panel (a)) $(33.827 \pm 0.223)$ was significantly lower 35 than that in unsuitable range $(194.589 \pm 0.019)$ (Mann-Whitney $U$ Test; $\left.p<2.2 \times 10^{-16}\right)$. Results 36 were expressed as mean \pm standard error. Coefficient of variation was calculated as follows: coefficient of variation $=$ standard deviation $/$ mean* $100 \%$. (c) Suitable range of $C$. savignyi under present-day climate conditions projected by ensemble SDM without considering water depth and distance to shore. 

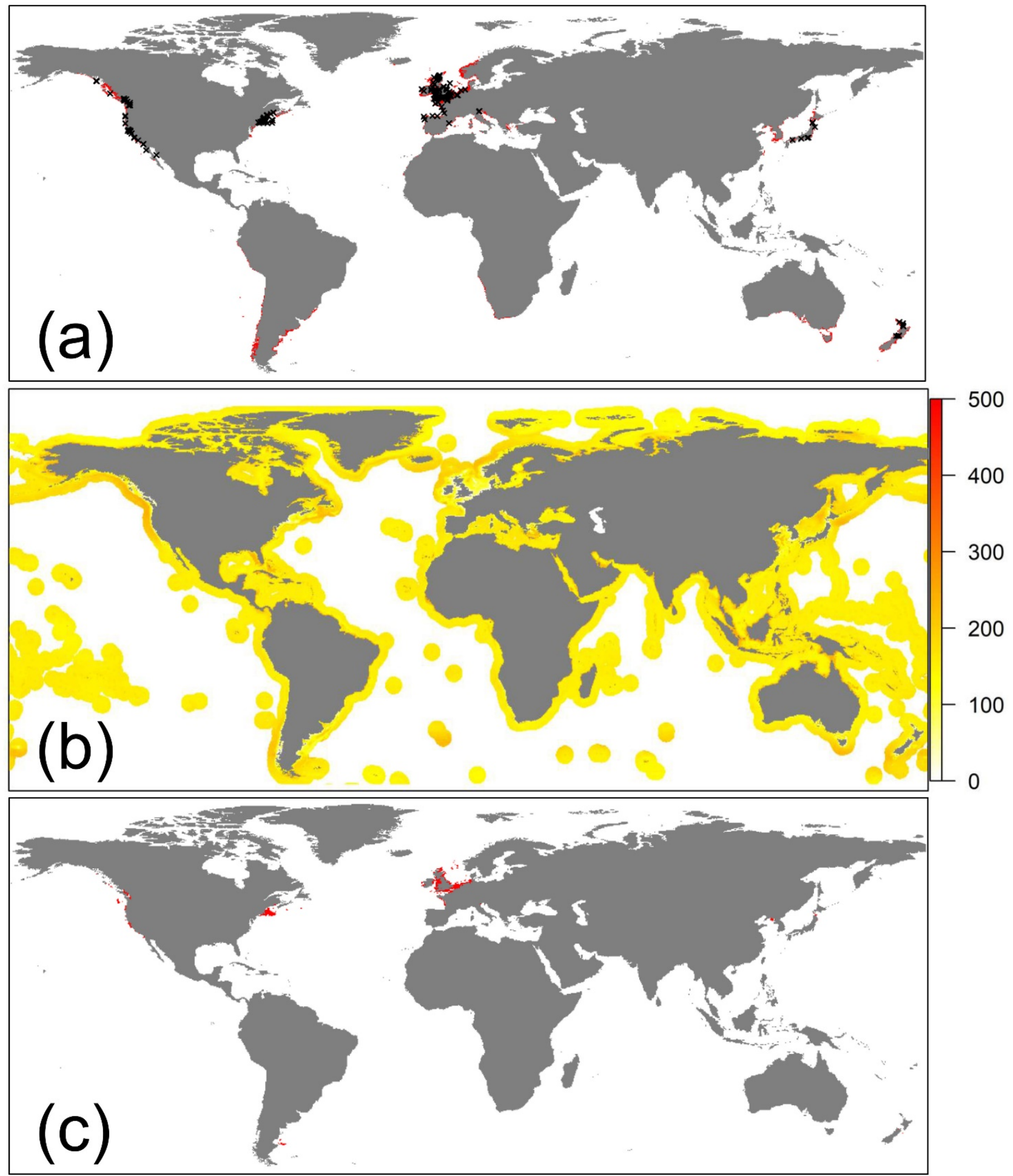

Figure S4. (a) Suitable range of Didemnum vexillum under present-day climate conditions projected by ensemble SDM. Red area represents suitable range. Black crosses indicate occurrence records of D. vexillum used to develop SDMs. 252 occurrence records of $D$. vexillum were used. (b) Coefficient of variation of present-day species occurrence probability predicted by seven single 
46 SDMs. Coefficient of variation in suitable range (i.e. red area in panel (a)) (46.178 \pm 0.157$)$ was 47 significantly lower than that in unsuitable range (156.493 \pm 0.016$)$ (Mann-Whitney $U$ Test; $p<$ $\left.2.2 \times 10^{-16}\right)$. Results were expressed as mean \pm standard error. Coefficient of variation was calculated as follows: coefficient of variation $=$ standard deviation $/$ mean* $100 \%$. (c) Suitable range of $D$. vexillum under present-day climate conditions projected by ensemble SDM without considering 51 water depth and distance to shore. 

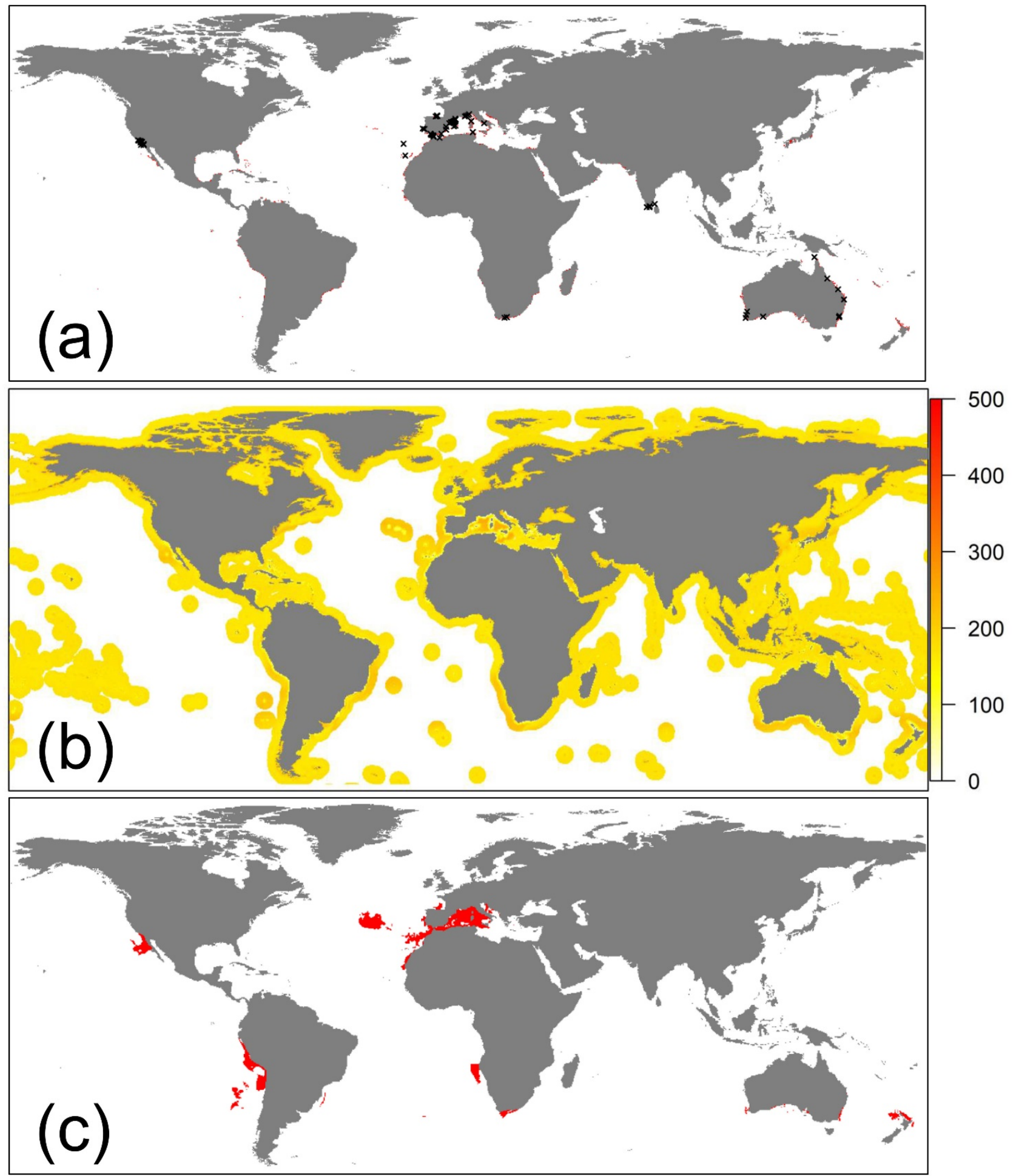

Figure S5. (a) Suitable range of Microcosmus squamiger under present-day climate conditions projected by ensemble SDM. Red area represents suitable range. Black crosses indicate occurrence records of M. squamiger used to develop SDMs. 77 occurrence records of M. squamiger were used. (b) Coefficient of variation of present-day species occurrence probability predicted by seven single 
58 SDMs. Coefficient of variation in suitable range (i.e. red area in panel (a)) (31.695 \pm 0.220$)$ was 59 significantly lower than that in unsuitable range (171.412 \pm 0.013$)$ (Mann-Whitney $U$ Test; $p<$

$\left.602.2 \times 10^{-16}\right)$. Results were expressed as mean \pm standard error. Coefficient of variation was calculated 61 as follows: coefficient of variation $=$ standard deviation $/$ mean* $100 \%$. (c) Suitable range of $M$. 62 squamiger under present-day climate conditions projected by ensemble SDM without considering 63 water depth and distance to shore.

64 

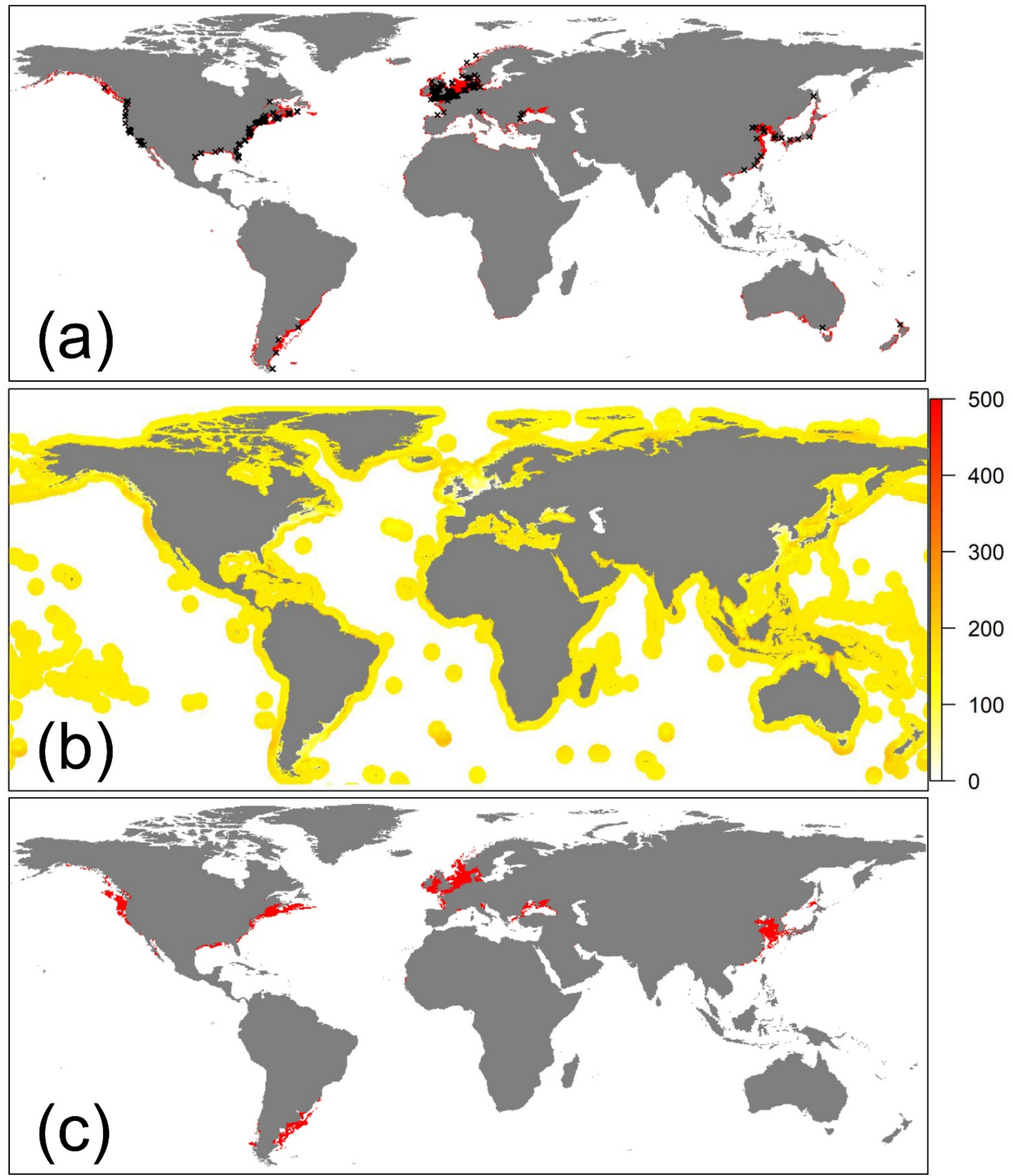

Figure S6. (a) Suitable range of Molgula manhattensis under present-day climate conditions projected by ensemble SDM. Red area represents suitable range. Black crosses indicate occurrence records of M. manhattensis used to develop SDMs. 368 occurrence records of M. manhattensis were used. (b) Coefficient of variation of present-day species occurrence probability predicted by 

seven single SDMs. Coefficient of variation in suitable range (i.e. red area in panel (a)) (51.039 \pm $0.108)$ was significantly lower than that in unsuitable range $(154.883 \pm 0.012)$ (Mann-Whitney $U$ Test; $\left.p<2.2 \times 10^{-16}\right)$. Results were expressed as mean \pm standard error. Coefficient of variation was calculated as follows: coefficient of variation $=$ standard deviation $/$ mean $* 100 \%$. (c) Suitable range of M. manhattensis under present-day climate conditions projected by ensemble SDM without considering water depth and distance to shore. 

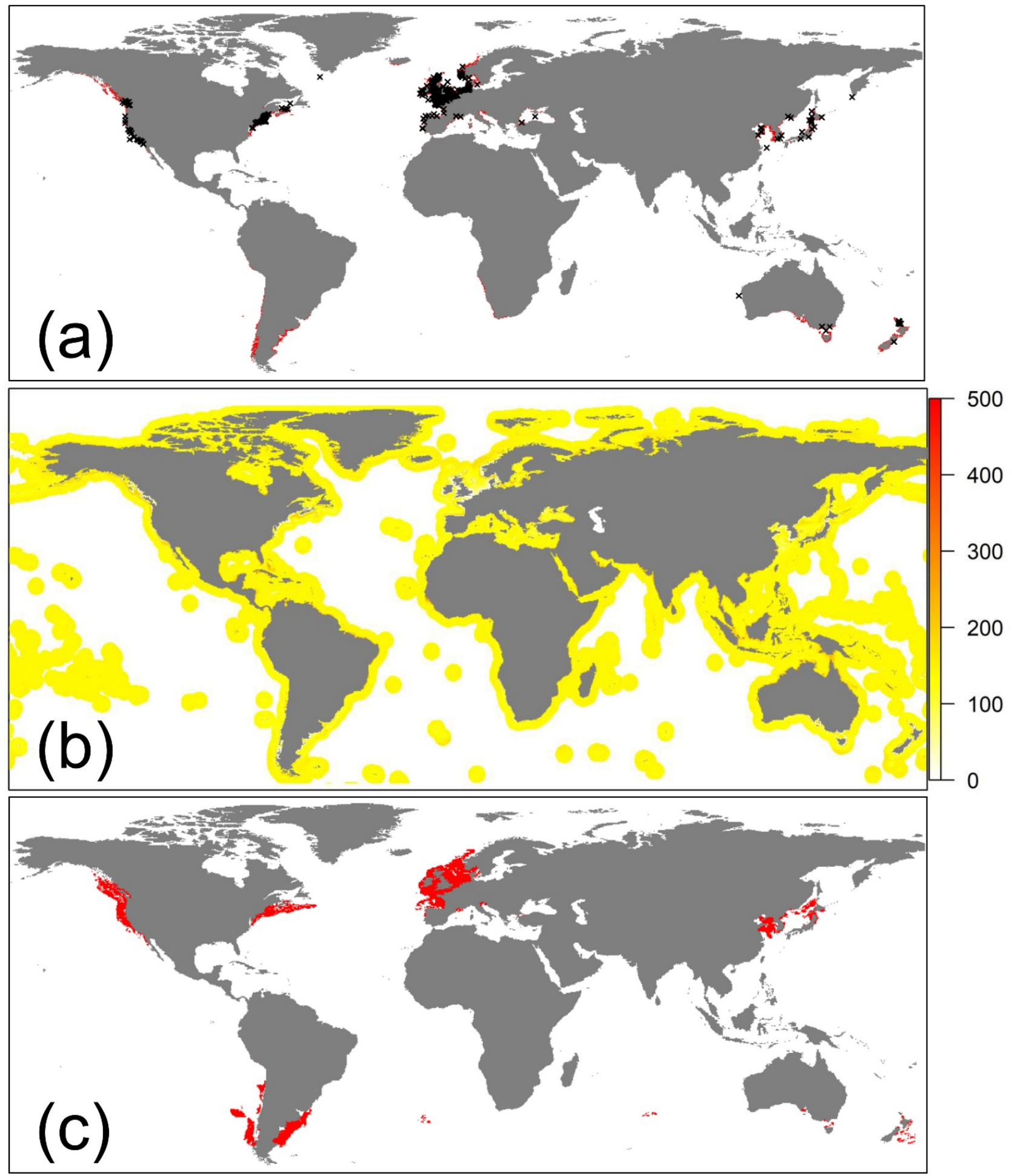

Figure S7. (a) Suitable range of Styela clava under present-day climate conditions projected by ensemble SDM. Red area represents suitable range. Black crosses indicate occurrence records of $S$. clava used to develop SDMs. 521 occurrence records of S. clava were used. (b) Coefficient of variation of present-day species occurrence probability predicted by seven single SDMs. Coefficient 
82 of variation in suitable range (i.e. red area in panel (a)) $(37.301 \pm 0.169)$ was significantly lower 83 than that in unsuitable range $(137.427 \pm 0.010)$ (Mann-Whitney $U$ Test; $\left.p<2.2 \times 10^{-16}\right)$. Results 84 were expressed as mean \pm standard error. Coefficient of variation was calculated as follows: coefficient of variation $=$ standard deviation $/$ mean $* 100 \%$. (c) Suitable range of $S$. clava under present-day climate conditions projected by ensemble SDM without considering water depth and 87 distance to shore. 

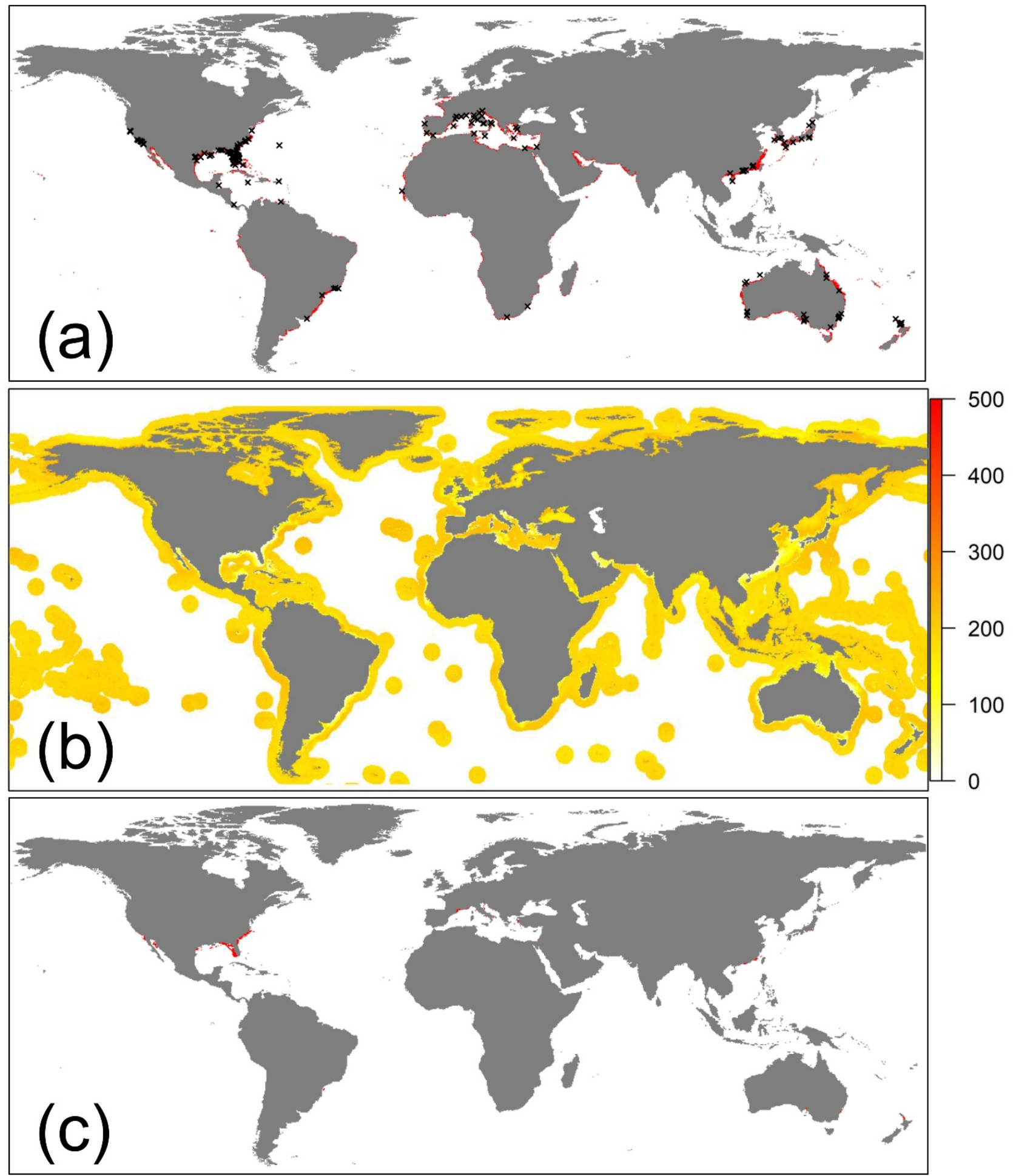

Figure S8. (a) Suitable range of Styela plicata under present-day climate conditions projected by ensemble SDM. Red area represents suitable range. Black crosses indicate occurrence records of $S$. plicata used to develop SDMs. 178 occurrence records of S. plicata were used. (b) Coefficient of variation of present-day species occurrence probability predicted by seven single SDMs. Coefficient 
94 of variation in suitable range (i.e. red area in panel (a)) $(39.872 \pm 0.101)$ was significantly lower 95 than that in unsuitable range $(184.213 \pm 0.016)$ (Mann-Whitney $U$ Test; $\left.p<2.2 \times 10^{-16}\right)$. Results were expressed as mean \pm standard error. Coefficient of variation was calculated as follows: coefficient of variation $=$ standard deviation $/$ mean $* 100 \%$. (c) Suitable range of S. plicata under present-day climate conditions projected by ensemble SDM without considering water depth and 99 distance to shore. 


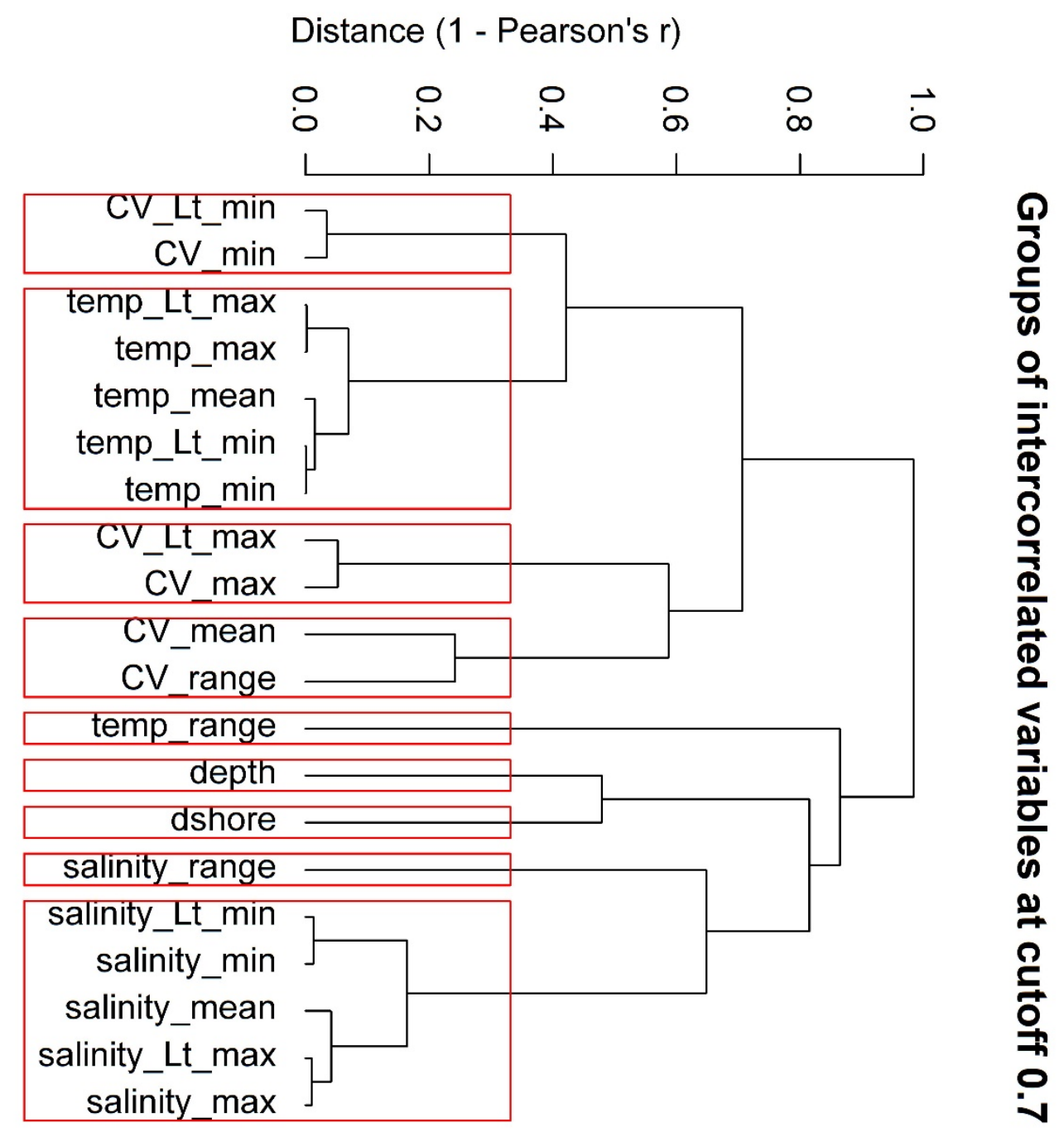

103 Figure S9. Collinearity analysis results of the twentyeight marine predictor variables. temp: annuat 104 sea surface temperature; Lt: mean values of the minimum and maximum records per year; CV:

105 current velocity. depth: water depth; dshore: distance to the shore. Detailed descriptions about 106 predictors can be found in Bio-ORACLE v2.0 (http://www.bio-oracle.org). Only one predictor was 107 selected among highly correlated predictors (i.e., Pearson's correlation coefficients $|r|>0.7$ ). 
109

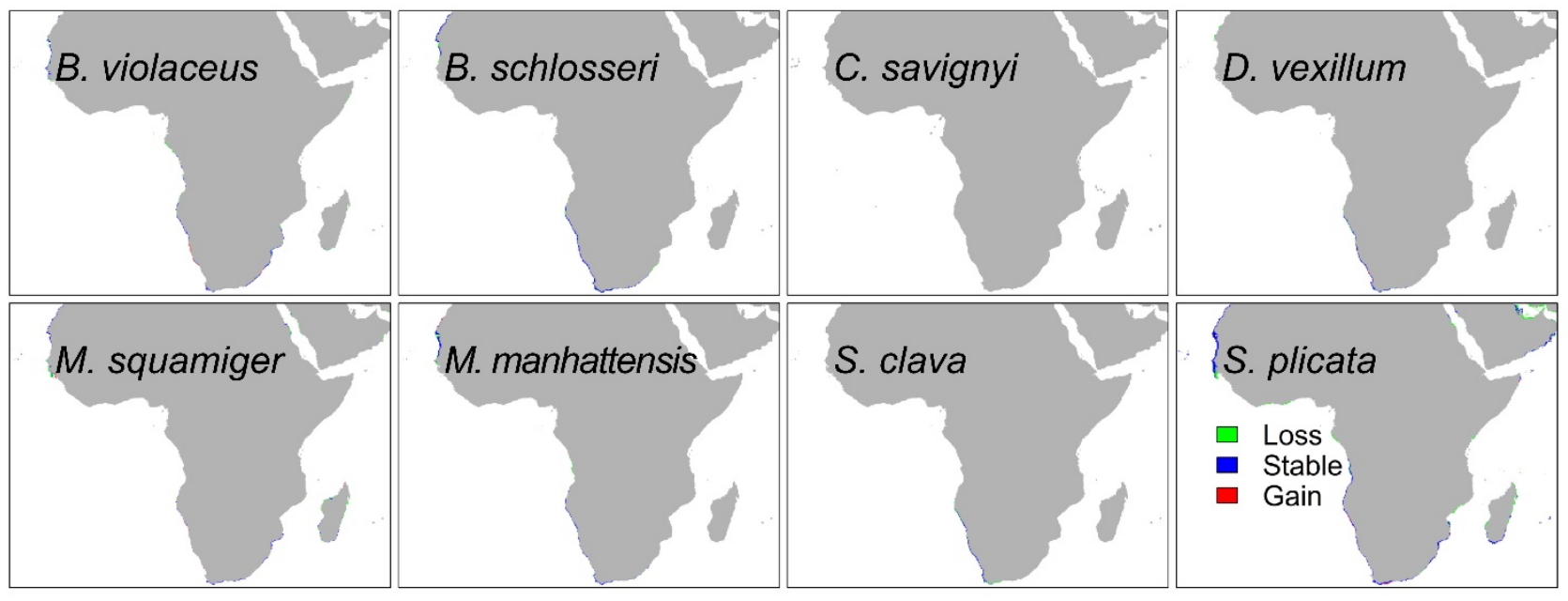

Figure S10. Predicted range shifts of the eight ascidians along African coastal areas in 2050s under RCP45 scenario. RCP: representative concentration pathway. 2050s: 2040-2050. Stable areas (in blue) indicate habitats that are predicted to be suitable under both present-day and future climates; loss areas (in green) show areas which are predicted no longer to be suitable in future; gain areas (in red) represent habitats that are predicted to be suitable in future.
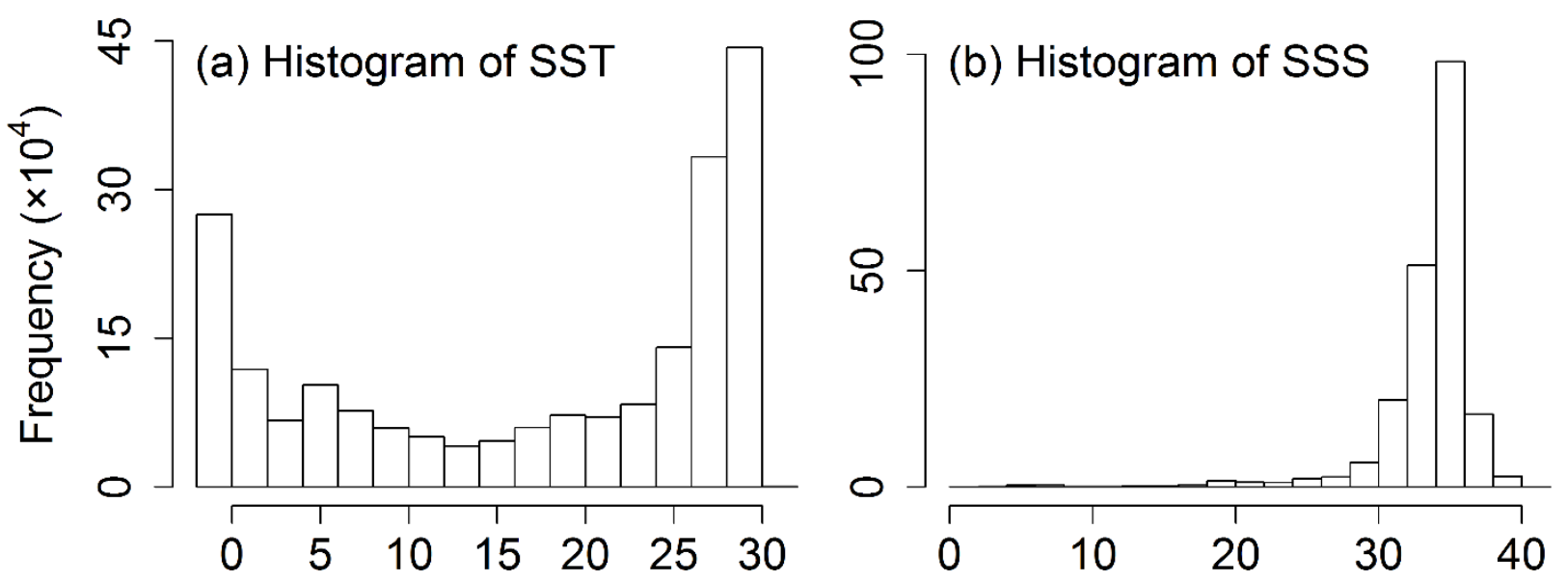

Figure S11. Frequency histograms of (a) mean sea surface temperature (SST) (in ${ }^{\circ} \mathrm{C}$ ) and (b) mean sea surface salinity (SST) (in \%o) within the Exclusive Economic Zone (i.e., within $370 \mathrm{~km}$ of the coast). SST is evenly distributed while SSS mainly concentrates between 30 to $38 \%$. 
Table S1 Mean ( \pm standard error) AUC values of the ten algorithms used to predict habitat suitability of eight ascidians. AUC: area under the receiver operating characteristic curve. AUC values were calculated by a five-fold cross-validation with 10 repetitions. The numbers in red represent algorithms with AUC < 0.90. ANN: artificial neural network, CTA: classification tree analysis, FDA: flexible discriminant analysis, GAM: generalized additive model, GBM: generalized boosting model, GLM: generalized linear model, MARS: multiple adaptive regression splines, Maxent: maximum entropy, RF: random forest, SRE: surface range envelop.

\begin{tabular}{|c|c|c|c|c|c|c|c|c|c|c|}
\hline Species & $\mathrm{ANN}$ & CTA & FDA & GAM & GBM & GLM & MARS & Maxent & $\mathrm{RF}$ & SRE \\
\hline \multirow[t]{2}{*}{ Botrylloides violaceus } & 0.979 & 0.951 & 0.979 & 0.975 & 0.991 & 0.991 & 0.990 & 0.916 & 0.989 & 0.845 \\
\hline & $( \pm 0.003)$ & $( \pm 0.008)$ & $( \pm 0.003)$ & $( \pm 0.003)$ & $( \pm 0.001)$ & $( \pm 0.001)$ & $( \pm 0.002)$ & $( \pm 0.006)$ & $( \pm 0.002)$ & $( \pm 0.010)$ \\
\hline \multirow[t]{2}{*}{ Botryllus schlosseri } & 0.984 & 0.970 & 0.982 & 0.988 & 0.991 & 0.988 & 0.990 & 0.945 & 0.993 & 0.868 \\
\hline & $( \pm 0.002)$ & $( \pm 0.002)$ & $( \pm 0.002)$ & $( \pm 0.002)$ & $( \pm 0.001)$ & $( \pm 0.001)$ & $( \pm 0.001)$ & $( \pm 0.005)$ & $( \pm 0.001)$ & $( \pm 0.006)$ \\
\hline \multirow[t]{2}{*}{ Ciona savignyi } & 0.989 & 0.951 & 0.991 & 0.925 & 0.996 & 0.980 & 0.984 & 0.893 & 0.998 & 0.786 \\
\hline & $( \pm 0.005)$ & $( \pm 0.011)$ & $( \pm 0.001)$ & $( \pm 0.018)$ & $( \pm 0.003)$ & $( \pm 0.006)$ & $( \pm 0.008)$ & $( \pm 0.015)$ & $( \pm 0.000)$ & $( \pm 0.013)$ \\
\hline \multirow[t]{2}{*}{ Didemnum vexillum } & 0.983 & 0.964 & 0.984 & 0.971 & 0.994 & 0.991 & 0.991 & 0.922 & 0.990 & 0.843 \\
\hline & $( \pm 0.002)$ & $( \pm 0.007)$ & $( \pm 0.002)$ & $( \pm 0.005)$ & $( \pm 0.001)$ & $( \pm 0.002)$ & $( \pm 0.002)$ & $( \pm 0.008)$ & $( \pm 0.002)$ & $( \pm 0.011)$ \\
\hline \multirow[t]{2}{*}{ Microcosmus squamiger } & 0.952 & 0.919 & 0.983 & 0.899 & 0.991 & 0.977 & 0.970 & 0.931 & 0.968 & 0.778 \\
\hline & $( \pm 0.010)$ & $( \pm 0.018)$ & $( \pm 0.001)$ & $( \pm 0.015)$ & $( \pm 0.001)$ & $( \pm 0.006)$ & $( \pm 0.008)$ & $( \pm 0.014)$ & $( \pm 0.008)$ & $( \pm 0.024)$ \\
\hline Molgula manhattensis & 0.982 & 0.955 & 0.981 & 0.983 & 0.994 & 0.987 & 0.992 & 0.925 & 0.994 & 0.832 \\
\hline
\end{tabular}


$\begin{array}{llllllllllll} \pm 0.002) & ( \pm 0.006) & ( \pm 0.002) & ( \pm 0.002) & ( \pm 0.001) & ( \pm 0.002) & ( \pm 0.001) & ( \pm 0.008) & ( \pm 0.001) & ( \pm 0.012)\end{array}$

$\begin{array}{lcccccccccccc}\text { Styela clava } & 0.982 & 0.966 & 0.988 & 0.986 & 0.993 & 0.993 & 0.994 & 0.950 & 0.992 & 0.866 \\ & ( \pm 0.004) & ( \pm 0.005) & ( \pm 0.001) & ( \pm 0.002) & ( \pm 0.001) & ( \pm 0.001) & ( \pm 0.001) & ( \pm 0.004) & ( \pm 0.001) & ( \pm 0.005) \\ \text { Styela plicata } & 0.977 & 0.931 & 0.977 & 0.959 & 0.991 & 0.985 & 0.984 & 0.952 & 0.992 & 0.810 \\ & ( \pm 0.005) & ( \pm 0.013) & ( \pm 0.003) & ( \pm 0.008) & ( \pm 0.001) & ( \pm 0.002) & ( \pm 0.003) & ( \pm 0.012) & ( \pm 0.001) & ( \pm 0.009)\end{array}$


131 range envelop.

\begin{tabular}{|c|c|c|c|c|c|c|c|c|c|c|}
\hline Species & ANN & CTA & FDA & GAM & GBM & GLM & MARS & Maxent & RF & SRE \\
\hline \multirow[t]{2}{*}{ Botrylloides violaceus } & 0.926 & 0.914 & 0.880 & 0.928 & 0.947 & 0.932 & 0.936 & 0.829 & 0.939 & 0.690 \\
\hline & $( \pm 0.009)$ & $( \pm 0.013)$ & $( \pm 0.010)$ & $( \pm 0.005)$ & $( \pm 0.005)$ & $( \pm 0.003)$ & $( \pm 0.007)$ & $( \pm 0.012)$ & $( \pm 0.006)$ & $( \pm 0.019)$ \\
\hline \multirow[t]{2}{*}{ Botryllus schlosseri } & 0.935 & 0.922 & 0.910 & 0.932 & 0.941 & 0.928 & 0.938 & 0.880 & 0.943 & 0.736 \\
\hline & $( \pm 0.003)$ & $( \pm 0.004)$ & $( \pm 0.005)$ & $( \pm 0.004)$ & $( \pm 0.003)$ & $( \pm 0.004)$ & $( \pm 0.003)$ & $( \pm 0.010)$ & $( \pm 0.002)$ & $( \pm 0.012)$ \\
\hline \multirow[t]{2}{*}{ Ciona savignyi } & 0.963 & 0.927 & 0.968 & 0.850 & 0.985 & 0.957 & 0.959 & 0.786 & 0.990 & 0.572 \\
\hline & $( \pm 0.010)$ & $( \pm 0.017)$ & $( \pm 0.005)$ & $( \pm 0.036)$ & $( \pm 0.006)$ & $( \pm 0.011)$ & $( \pm 0.016)$ & $( \pm 0.030)$ & $( \pm 0.001)$ & $( \pm 0.025)$ \\
\hline \multirow[t]{2}{*}{ Didemnum vexillum } & 0.924 & 0.934 & 0.897 & 0.924 & 0.948 & 0.956 & 0.958 & 0.843 & 0.944 & 0.685 \\
\hline & $( \pm 0.009)$ & $( \pm 0.011)$ & $( \pm 0.009)$ & $( \pm 0.009)$ & $( \pm 0.008)$ & $( \pm 0.005)$ & $( \pm 0.004)$ & $( \pm 0.017)$ & $( \pm 0.009)$ & $( \pm 0.022)$ \\
\hline \multirow[t]{2}{*}{ Microcosmus squamiger } & 0.872 & 0.843 & 0.912 & 0.792 & 0.920 & 0.920 & 0.902 & 0.844 & 0.879 & 0.555 \\
\hline & $( \pm 0.027)$ & $( \pm 0.032)$ & $( \pm 0.008)$ & $( \pm 0.028)$ & $( \pm 0.017)$ & $( \pm 0.018)$ & $( \pm 0.016)$ & $( \pm 0.024)$ & $( \pm 0.017)$ & $( \pm 0.048)$ \\
\hline Molgula manhattensis & 0.929 & 0.910 & 0.891 & 0.928 & 0.939 & 0.927 & 0.934 & 0.843 & 0.942 & 0.664 \\
\hline
\end{tabular}


$\begin{array}{lllllllllll} \pm 0.008) & ( \pm 0.008) & ( \pm 0.006) & ( \pm 0.006) & ( \pm 0.004) & ( \pm 0.004) & ( \pm 0.005) & ( \pm 0.015) & ( \pm 0.007) & ( \pm 0.025)\end{array}$

$\begin{array}{lcccccccccccc}\text { Styela clava } & 0.934 & 0.938 & 0.908 & 0.943 & 0.956 & 0.949 & 0.955 & 0.896 & 0.951 & 0.733 \\ & ( \pm 0.009) & ( \pm 0.005) & ( \pm 0.007) & ( \pm 0.005) & ( \pm 0.004) & ( \pm 0.004) & ( \pm 0.003) & ( \pm 0.008) & ( \pm 0.004) & ( \pm 0.010) \\ \text { Styela plicata } & 0.898 & 0.875 & 0.894 & 0.891 & 0.940 & 0.926 & 0.938 & 0.881 & 0.928 & 0.621 \\ & ( \pm 0.009) & ( \pm 0.014) & ( \pm 0.010) & ( \pm 0.013) & ( \pm 0.009) & ( \pm 0.006) & ( \pm 0.010) & ( \pm 0.022) & ( \pm 0.010) & ( \pm 0.017)\end{array}$

